\title{
Study of the Bullwhip Effect under Various Forecasting Methods in Electronics Supply Chain with Dual Retailers considering Market Share
}

\author{
Junhai Ma $\mathbb{D}^{1}{ }^{1}$ Jing Zhang, ${ }^{1}$ and Liqing Zhu $\mathbb{D}^{1,2}$ \\ ${ }^{1}$ College of Management and Economics, Tianjin University, Tianjin 300072, China \\ ${ }^{2}$ School of HUAXIN Software, Tianjin University of Technology, Tianjin 300384, China \\ Correspondence should be addressed to Liqing Zhu; Lqzhu20080818@126.Com
}

Received 13 April 2017; Accepted 17 July 2017; Published 8 January 2018

Academic Editor: Soheil Salahshour

Copyright ( $\odot 2018$ Junhai Ma et al. This is an open access article distributed under the Creative Commons Attribution License, which permits unrestricted use, distribution, and reproduction in any medium, provided the original work is properly cited.

We establish in this paper a new two-stage supply chain with one manufacturer and two retailers which have a fixed market share in the mature and stable market with specific reference to consumer electronics industry. This paper offers insights into how the three forecasting methods affect the bullwhip effect considering the market share under the ARMA $(1,1)$ demand process and the orderup-to inventory policy. We also discuss the stability of the order with the theory of entropy. In particular, we derive the expressions of bullwhip effect measure under the MMSE, MA, and ES methods and compare them by numerical simulations. Results show that the MA is always better in contrast to the ES for reducing the bullwhip effect in our supply chain model. When moving average coefficient is lower than a certain value, the MMSE method is the best for reducing the bullwhip effect; otherwise, the MA method is the best. Moreover, the larger the market share of the retailer with a long lead time is, the greater the bullwhip effect is, no matter what the forecasting method is.

\section{Introduction}

There is a high-risk behavior occurring frequently in many companies' marketing activities, which is called bullwhip effect, first coined by Lee et al. [1,2]. It affects operational costs and may lead to chaos in the system. Because of its impact on the operation and management strategies of all the upstream and downstream enterprises, it has become a focus in the supply chain management research. In this paper, we focus on the consumer electronics supply chain management, which is characterized by frequent channel competition. In the Chinese consumer electronics offline retail market, GOME and SUNING are two giant chain enterprises, which occupy more than $45 \%$ of the market share. Most of the consumer electronics manufacturers sell products through these two home appliance retail chain stores. The market demand forecasting and replenishment strategies of the two retail giants will undoubtedly affect order fluctuations and production plan of the manufacturers. We assume that the demand is independent because GOME is far apart from SUNING.
So, we use the $\operatorname{ARMA}(1,1)$ demand process and aim to investigate the effect of three forecasting methods on the bullwhip effect considering the market share.

Bullwhip effect refers to a phenomenon where the order variability tends to be amplified in a supply chain from the downstream member to its (immediate) upstream member. Forrester [3,4] discovered bullwhip effect's causes and possible remediation by industrial dynamics and became the first scholar proving this phenomenon. This was the first milestone in the academic research of bullwhip effect. Then, many other researchers further proved the existence of the bullwhip effect. A well-known classic "beer game" experimented on by Sterman [5] is the second milestone which has been utilized in business schools for decades to illustrate the bullwhip effect. The third milestone, also very important, is the statistical research stage which was started by Lee et al. [1, 2]. He identified five main causes of the bullwhip effect which are demand signal processing, supply shortage, nonzero lead time, price fluctuation, and order batching in supply chains. After that, more and more researchers studied 
the bullwhip effect by statistical methods. Based on the works of Lee, different demand processes and forecasting methods which directly affected the inventory system of supply chains significantly are employed in a lot of papers.

Similar to Lee et al. [1,2], many papers are published for an AR(1) demand model in a two-stage supply chain with one manufacturer and one retailer [6-10]. Chen et al. $[6,7]$ studied the difference of bullwhip effects under two forecasting methods (MA and ES) in a simple, two-stage supply chain. Zhang [8] investigated the impact of three different forecasting methods (MA, ES, and MMSE) on the bullwhip effect under AR(1) demand process. Lee et al. [9] also measured the benefit of information sharing on reducing the bullwhip effect using $\mathrm{AR}(1)$ process and a simple order-upto inventory policy with the minimum mean square error (MMSE) forecasting technique. Likewise, Luong [10] used the same demand model as Lee et al. [9] to measure the bullwhip effect on the base stock policy for their inventory under the MMSE forecasting technique. Furthermore, Luong and Phien [11] investigated AR(2) demand process and higher order autoregressive models $\mathrm{AR}(p)$ with the MMSE method. By calculating the bullwhip effect, these papers investigated effects of different parameters on the bullwhip effect, such as autoregressive coefficients and order lead time. In addition, Duc et al. [12] measured the impact of a third-party warehouse on the bullwhip effect and inventory cost under AR(1) process in a three-stage supply chain with one manufacturer, one third-party warehouse, and two retailers considering market share.

A pure autoregressive process has been supposed by a few academics [1, 2, 6-12], and a pure moving average process has also been used by Graves [13]. However, we can get that the demand model has both characteristics of them. Pindyck and Rubinfeld [14] assumed the mixed autoregressive-moving average (ARMA) demand process which is more suitable for the market demand than AR(1) model. Then, the ARMA process is frequently applied. Under the base stock policy, Disney et al. [15] used $\operatorname{ARMA}(1,1)$ demand pattern to measure the bullwhip effect by the ES forecasting method in a single supply chain echelon. Duc et al. [16] focused on the impact of some parameters on the bullwhip effect via an $\operatorname{ARMA}(1,1)$ model by the MMSE method. Likewise, Feng and Ma [17] evaluated the difference of MA, ES, and MMSE forecasting methods, with the $\operatorname{ARMA}(1,1)$ model by using the dynamic simulation. The $\operatorname{ARMA}(1,1)$ demand model is applied in all the above papers in a single supply chain with one manufacturer and one retailer. But, as an extension, a new supply chain with one manufacturer and two retailers who both employ the $\operatorname{ARMA}(1,1)$ demand process is made, and emphasis is put on the competition between the two retailers analyzed $[18,19]$. This model also compared the impact of parameters on the bullwhip effect under various forecasting methods. Moreover, Bandyopadhyay and Bhattacharya [20] primarily studied the various replenishment policies to derive expressions of BWE based on the generalized $\operatorname{ARMA}(p, q)$ demand process in order to get the appropriate replenishment policy for the minimum BWE.

As a further expansion of the ARMA demand model, Gilbert [21] conducted a new Autoregressive Integrated
Moving Average (ARIMA) time-series model to present the causes of the bullwhip effect and managerial insights about reducing the bullwhip effect in a multistage supply chain model. Dhahri and Chabchoub (2007) also used an ARIMA demand pattern to alleviate the bullwhip effect in two aspects of increase of the stock level and reduction of the service given back to customers. Nagaraja et al. [22] measured the bullwhip measure for a two-stage supply chain with an orderup-to inventory policy and derived a general, stationary $\operatorname{SARMA}(p, q) \times(P, Q))_{s}$ demand process.

Many scholars research the systematic problem combining the entropy theory. By using the tool of entropy, Han et al. [23] built a duopoly game model and investigated how the time delay influences the stability of the system. Ma and Si [24] researched a Bertrand duopoly game model with twostage delay and discussed the stability of the economic system.

This paper derives the expressions of the bullwhip effect under various forecasting methods in a two-stage mature and stable supply chain with one manufacturer and two retailers which have a fixed market share. With the development of information technology, all electronic manufacturers take strategies to shorten the length of supply chain and take new information technologies to speed up the logistics. For instance, Haier, one of the largest household electrical appliances manufacturers all over the world, has been benefiting from the application of ERP and BBP since the beginning of the 21st century. The information management system performs information synchronization and integration, improves the real-time and accuracy of the information, and speeds up the response speed of the supply chain. Therefore, the flat supply chain is common in reality. Based on this, we assume that both retailers face an $\operatorname{ARMA}(1,1)$ demand process and employ the order-up-to replenishment policy. In the current research, we analyze the impact of parameters on the BWE under the MMSE, MA, and ES forecasting methods and compare the differences of the three methods on dampening the bullwhip effect.

This paper differs from the previous research in the following. First, the ARMA $(1,1)$ demand model of two retailers with a certain market share which is not considered in previous papers is established in a mature and stable product market. Second, this paper evaluates the impact of the market share on the bullwhip effect and compares three forecasting methods in this two-stage supply chain.

The remaining part of this paper is organized as follows. In Section 2, we present the demand process with the market share in a new supply chain with one manufacturer and two retailers which both employ the order-up-to inventory policy. In Section 3, we derive the bullwhip effect measure under MMSE, MA, and ES forecasting methods. Under different forecasting methods, the behavior of the bullwhip effect is investigated and the effects of parameters on the bullwhip effect are discussed in Section 4, and then we compare the impact of the three forecasting methods on the bullwhip effect by numerical simulations. Finally, a short conclusion is stated for this paper in Section 5. Proofs of some propositions in this paper are summarized in the Appendix. 


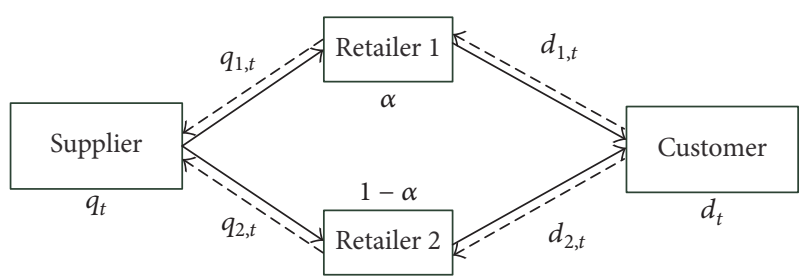

FIgURE 1: Two-stage supply chain model.

\section{Supply Chain Model}

The two-level supply chain model shown in Figure 1, consisting of one manufacturer with a distribution center and two retailers in the same market, is common in the consumer electronics industry. A hypothesis is that the supply chain is in a stable market. So, we assume that our two retailers are in a duopolistic competitive industry, who both have fixed share of the market of customer demand, $\alpha$ and $1-\alpha$, respectively. The two retailers both master the accurate market information and their customer demands, which are $\operatorname{ARMA}(1,1)$ processes, and place orders to the manufacturer, respectively. The manufacturer obtains the orders directly from the retailers and arranges the delivery to the nearest distribution center as soon as possible, and the retailers take the products back immediately once what they ordered has arrived. The new supply chain model is presented in this section.

2.1. Demand Process. Consider retailer 1 facing an $\operatorname{ARMA}(1,1)$ demand of the form

$$
d_{1, t}=\alpha \delta+\phi d_{1, t-1}+\alpha \varepsilon_{t}-\alpha \theta \varepsilon_{t-1} .
$$

Here, $d_{1, t}$ represents unit demand in the period $t . \phi$ is the autoregressive coefficient, and $|\phi|<1 . \theta$ is the first-order moving average coefficient, where $-1<\theta<1$. $\varepsilon_{t}$ is the random error of the customer demand, and $\varepsilon_{t}$ is independent and identically distributed from a normal distribution with mean 0 and variance $\sigma^{2} . \alpha$ is the market share of retailer 1 .

Since the demand process is stationary, there is

$$
\begin{gathered}
E\left(d_{1, t}\right)=E\left(d_{1, t-1}\right)=E\left(d_{1}\right), \\
\operatorname{Var}\left(d_{1, t}\right)=\operatorname{Var}\left(d_{1, t-1}\right)=\operatorname{Var}\left(d_{1}\right),
\end{gathered}
$$

$\forall t$.

Hence, a stationary condition can be given as

$$
\begin{aligned}
E\left(d_{1}\right) & =\frac{\alpha \delta}{1-\phi} . \\
\operatorname{Var}\left(d_{1}\right) & =\frac{\alpha^{2}\left(1+\theta^{2}-2 \phi \theta\right)}{1-\phi^{2}} \operatorname{Var}\left(\varepsilon_{t}\right) .
\end{aligned}
$$

Similarly, retailer 2 also has an $\operatorname{ARMA}(1,1)$ demand model

$$
d_{2, t}=(1-\alpha) \delta+\phi d_{2, t-1}+(1-\alpha) \varepsilon_{t}-(1-\alpha) \theta \varepsilon_{t-1} .
$$

Here, $\phi$ and $\theta$ have the same property with retailer 1 accordingly. $1-\alpha$ is the market share of retailer 2 .

For retailer 2, we also assume

$$
\begin{gathered}
E\left(d_{2, t}\right)=E\left(d_{2, t-1}\right)=E\left(d_{2}\right), \\
\operatorname{Var}\left(d_{2, t}\right)=\operatorname{Var}\left(d_{2, t-1}\right)=\operatorname{Var}\left(d_{2}\right),
\end{gathered}
$$

$\forall t$.

So, we can have

$$
\begin{aligned}
E\left(d_{2}\right) & =\frac{(1-\alpha) \delta}{1-\phi} \\
\operatorname{Var}\left(d_{2}\right) & =\frac{(1-\alpha)^{2}\left(1+\theta^{2}-2 \phi \theta\right)}{1-\phi^{2}} \operatorname{Var}\left(\varepsilon_{t}\right) .
\end{aligned}
$$

In our research, based on the demand models of two retailers, the total customer demand $d_{t}$ also faces an $\operatorname{ARMA}(1,1)$, as follows:

$$
d_{t}=\delta+\phi d_{t-1}+\varepsilon_{t}-\theta \varepsilon_{t-1} .
$$

Then, we have

$$
\begin{aligned}
& d_{1, t}=\alpha d_{t}, \\
& d_{2, t}=(1-\alpha) d_{t} .
\end{aligned}
$$

2.2. Inventory Policy. For supplying the demand, we assume the order-up-to inventory policy during the replenishment period, which is studied in the supply chain model by Chen et al. [6]. This paper assumes that two retailers both employ a simple order-up-to inventory policy in which the orderup-to level is determined to achieve a desired service level. Retailer 1 places an ordered quantity $q_{1, t}$ to the manufacturer at the beginning of period $t$ to be delivered at the beginning of period $t+L_{1}$, where $L_{1}$ is the fixed lead time for the manufacturer to fulfill an order of retailer 1 . The order quantity $q_{1, t}$ can be given as

$$
q_{1, t}=S_{1, t}-S_{1, t-1}+d_{1, t-1} \text {, }
$$

where $S_{1, t}$ is the order-up-to inventory position at the beginning of period $t$ of retailer 1 after placing the order in period $t$. While the base stock policy [16] is employed, the order-up-to level $S_{1, t}$ can be determined by the sum of forecasted leadtime demand and the safety stock as

$$
S_{1, t}=\widehat{D}_{1, t}^{L_{1}}+z \widehat{\sigma}_{1, t}^{L_{1}}
$$

in which $\widehat{D}_{1, t}^{L_{1}}$ is the forecast for the lead-time demand of retailer 1 which depends on the forecasting method and lead time $L_{1}, \widehat{\sigma}_{1, t}^{L_{1}}$ is the standard deviation of lead-time demand forecast error, and $z$ is the normal $z$ score determined based on a desired service level (the optimal order-up-to level $S_{t}$ can be implicitly determined from inventory holding cost and shortage cost for backorders (Heyman and Sobel, 1984 [8]); however, since it is usually not easy to estimate these costs accurately in practice, the approach of using the service 
levels is often employed when the order-up-to level is to be determined).

Similarly, for retailer 2 , the order quantity $q_{2, t}$, which is placed to the manufacturer in period $t$ to be delivered at the beginning of period $t+L_{2}$, where $L_{2}$ is the fixed lead time of retailer 1 , can be given as

$$
q_{2, t}=S_{2, t}-S_{2, t-1}+d_{2, t-1}
$$

The order-up-to level of retailer 2 at period $t$ is

$$
S_{2, t}=\widehat{D}_{2, t}^{L_{1}}+z \widehat{\sigma}_{2, t}^{L_{1}}
$$

Equations (11)-(12) have the same meaning as (9)-(10).

2.3. Forecasting Method. In this paper, we assume that two retailers both use the same forecasting method to forecast the lead-time demand. Commonly, there are three forecasting techniques, MA, ES, and MMSE, for demand forecast. As mentioned above, they have been used in most similar researches. Here, in our paper, according to the demand process, we choose appropriate forecasting methods.

In Section 3, the bullwhip effect will be measured, respectively, under the MMSE, MA, and ES forecasting methods. Those three forecasting methods will be introduced in this section firstly.

2.3.1. The MMSE Forecasting Method. In the minimum mean square error (MMSE) forecasting method, the lead-time demand forecast $\widehat{D}_{t}^{L}$ is given as

$$
\widehat{D}_{t}^{L}=\widehat{d}_{t}+\widehat{d}_{t+1}+\cdots+\widehat{d}_{t+L-1}=\sum_{i=0}^{L-1} \widehat{d}_{t+i}
$$

where $\widehat{d}_{t}$ is the forecast of the demand in period $t$, which can be determined as

$$
\widehat{d}_{t+i}=E\left[d_{t+i} \mid d_{t-1}, d_{t-2}, \ldots\right]
$$

Under the $\operatorname{ARMA}(1,1)$ model, we can have the customer demand in the period of $t+i$ by the recursive iteration of $d_{t}$ based on (7):

$$
\begin{aligned}
d_{t+i}= & \frac{1-\phi^{i+1}}{1-\phi} \delta+\phi^{i+1} d_{t-1}-\theta \sum_{j=0}^{i} \phi^{j} \varepsilon_{t+i-j-1} \\
& +\sum_{j=0}^{i} \phi^{j} \varepsilon_{t+i-j} .
\end{aligned}
$$

Then, the forecasting of the demand $d_{t+i}$ by the MMSE method is as follows:

$$
\widehat{d}_{t+i}=\frac{1-\phi^{i+1}}{1-\phi} \delta+\phi^{i+1} d_{t-1}-\phi^{i} \theta \varepsilon_{t-1}
$$

According to (13) and (16), the total forecasting demand for future $L$-periods can be simplified as

$$
\begin{aligned}
\widehat{D}_{t}^{L}= & \frac{L}{1-\phi} \delta-\frac{\phi\left(1-\phi^{L}\right)}{(1-\phi)^{2}} \delta+\frac{\phi\left(1-\phi^{L}\right)}{1-\phi} d_{t-1} \\
& -\frac{\theta\left(1-\phi^{L}\right)}{1-\phi} \varepsilon_{t-1} .
\end{aligned}
$$

2.3.2. The MA Forecasting Method. Using the moving average (MA) forecasting method, we first have the $\tau$-period-ahead demand forecast given by

$$
\widehat{d}_{t+\tau}=\widehat{d}_{t}=\frac{1}{k} \sum_{i=1}^{k} d_{t-i}, \quad \tau \geq 1,
$$

in which $k$ is the span (number of date points) for the MA forecasting method. Then, the lead-time demand forecast is given as

$$
\widehat{D}_{t}^{L}=\frac{L}{k} \sum_{i=1}^{k} d_{t-i}
$$

2.3.3. The ES Forecasting Method. The ES forecasting method is an adaptive algorithm in which one-period-ahead forecast is adjusted with a fraction of the forecasting error. The demand forecast with ES can be written as

$$
\widehat{d}_{t}=\lambda d_{t-1}+(1-\lambda) \widehat{d}_{t-1}
$$

where $\lambda$ denotes the fraction used in this process, also called the smoothing factor, and $0<\lambda<1$.

\section{Measure of Bullwhip Effect considering Market Share}

In this section, we derive the measure of the bullwhip effect in a supply chain with one manufacturer and two retailers which both have stable market share, under the MMSE, MA, and ES forecasting methods mentioned above, respectively. From an early start, the bullwhip effect is a phenomenon in which the variance of demand information is amplified when moving upstream in a supply chain. Thus, it is reasonable to measure the bullwhip effect by the ratio of the variance of order quantities experienced by the manufacturer to the actual variance of demand quantities. This means has been used in previous researches such as those of Chen et al. [6, 7] and Duc et al. [12], and it is adopted in our research as well.

In our model, according to (7)-(8), the total demand of retailers $d_{t}$ is distributed as the $\operatorname{ARMA}(1,1)$ model. Take the variance of $d_{t}$; we have

$$
\operatorname{Var}\left(d_{t}\right)=\frac{\left(1+\theta^{2}-2 \phi \theta\right)}{1-\phi^{2}} \operatorname{Var}\left(\varepsilon_{t}\right)
$$


3.1. Measure of the Bullwhip Effect under the MMSE Forecasting Method. As stated in Section 3.2, the order of retailer $1 q_{1, t}$ can be given as

$$
\begin{aligned}
q_{1, t} & =S_{1, t}-S_{1, t-1}+d_{1, t-1} \\
& =\widehat{D}_{1, t}^{L_{1}}-\widehat{D}_{1, t-1}^{L_{1}}+z\left(\widehat{\sigma}_{1, t}^{L_{1}}-\widehat{\sigma}_{1, t-1}^{L_{1}}\right)+d_{1, t-1}
\end{aligned}
$$

According to (17), the forecasting of the lead-time demand for retailer 1 is

$$
\begin{aligned}
\widehat{D}_{1, t}^{L_{1}}= & \frac{L_{1}}{1-\phi} \alpha \delta-\frac{\phi\left(1-\phi^{L_{1}}\right)}{(1-\phi)^{2}} \alpha \delta+\frac{\phi\left(1-\phi^{L_{1}}\right)}{1-\phi} d_{1, t-1} \\
& -\frac{\alpha \theta\left(1-\phi^{L_{1}}\right)}{1-\phi} \varepsilon_{t-1} .
\end{aligned}
$$

And the variance of lead-time demand forecast error, $\widehat{\sigma}_{1, t}^{L_{1}}$, does not depend on $t$.

Thus, taking (23) into (22), $q_{1, t}$ can be determined as

$$
\begin{aligned}
q_{1, t}= & \frac{\phi\left(1-\phi^{L_{1}}\right)}{1-\phi} d_{1, t-1}-\frac{\alpha \theta\left(1-\phi^{L_{1}}\right)}{1-\phi} \varepsilon_{t-1} \\
& -\left(\frac{\phi\left(1-\phi^{L_{1}}\right)}{1-\phi} d_{1, t-2}-\frac{\alpha \theta\left(1-\phi^{L_{1}}\right)}{1-\phi} \varepsilon_{t-2}\right) \\
& +d_{1, t-1} \\
= & \left(\phi A_{1}+1\right) d_{1, t-1}-\phi A_{1} d_{1, t-2} \\
& -\alpha \theta A_{1}\left(\varepsilon_{t-1}-\varepsilon_{t-2}\right)
\end{aligned}
$$

where $A_{1}=\left(1-\phi^{L_{1}}\right) /(1-\phi)$.

Since $d_{1, t}=\alpha d_{t}, q_{1, t}$ can be rewritten as

$$
\begin{aligned}
q_{1, t}= & \left(\phi A_{1}+1\right) \alpha d_{t-1}-\phi A_{1} \alpha d_{t-2} \\
& -\alpha \theta A_{1}\left(\varepsilon_{t-1}-\varepsilon_{t-2}\right) .
\end{aligned}
$$

Likewise, we also have $\widehat{\sigma}_{2, t}^{L_{2}}=\widehat{\sigma}_{2, t-1}^{L_{2}}$, and based on (24) and $d_{2, t}=(1-\alpha) d_{t}$, the order of retailer 2 in period $t$ can be written as

$$
\begin{aligned}
q_{2, t}= & \left(\phi A_{2}+1\right)(1-\alpha) d_{t-1}-\phi A_{2}(1-\alpha) d_{t-2} \\
& -(1-\alpha) \theta A_{2}\left(\varepsilon_{t-1}-\varepsilon_{t-2}\right)
\end{aligned}
$$

where $A_{2}=\left(1-\phi^{L_{2}}\right) /(1-\phi)$.
In this way, the order quantity of both retailers under the MMSE forecasting method in the period of $t$ is

$$
\begin{aligned}
q_{t}= & q_{1, t}+q_{2, t} \\
= & \left(\phi A_{1}+1\right) \alpha d_{t-1}-\phi A_{1} \alpha d_{t-2} \\
& -\alpha \theta A_{1}\left(\varepsilon_{t-1}-\varepsilon_{t-2}\right)+\left(\phi A_{2}+1\right)(1-\alpha) d_{t-1} \\
& -\phi A_{2}(1-\alpha) d_{t-2}-(1-\alpha) \theta A_{2}\left(\varepsilon_{t-1}-\varepsilon_{t-2}\right) \\
= & \left(1+\alpha \phi A_{1}+(1-\alpha) \phi A_{2}\right) d_{t-1} \\
& -\left(\alpha \phi A_{1}+(1-\alpha) \phi A_{2}\right) d_{t-2} \\
& -\left(\alpha \theta A_{1}+(1-\alpha) \theta A_{2}\right) \varepsilon_{t-1} \\
& +\left(\alpha \theta A_{1}+(1-\alpha) \theta A_{2}\right) \varepsilon_{t-2} .
\end{aligned}
$$

Proposition 1. The variance of total order quantity of two retailers under the MMSE forecasting method in the period of $t$ can be determined as

$$
\begin{aligned}
& \operatorname{Var}\left(q_{t}\right)=\left[\left(1+\alpha \phi A_{1}+(1-\alpha) \phi A_{2}\right)^{2}+\left(\alpha \phi A_{1}\right.\right. \\
& \left.+(1-\alpha) \phi A_{2}\right)^{2}-2\left(1+\alpha \phi A_{1}+(1-\alpha) \phi A_{2}\right) \\
& \cdot\left(\alpha \phi A_{1}+(1-\alpha) \phi A_{2}\right) \frac{(\phi-\theta)(1-\phi \theta)}{1+\theta^{2}-2 \phi \theta}+2 \\
& \cdot \frac{1-\phi^{2}}{1+\theta^{2}-2 \phi \theta}\left(\left(\alpha \theta A_{1}+(1-\alpha) \theta A_{2}\right)^{2}\right. \\
& -\left(1+\alpha \phi A_{1}+(1-\alpha) \phi A_{2}\right)\left(\alpha \theta A_{1}+(1-\alpha) \theta A_{2}\right) \\
& +\left(1+\alpha \phi A_{1}+(1-\alpha) \phi A_{2}\right)\left(\alpha \theta A_{1}+(1-\alpha) \theta A_{2}\right) \\
& \cdot(\phi-\theta)-\left(\alpha \phi A_{1}+(1-\alpha) \phi A_{2}\right) \\
& \left.\left.\cdot\left(\alpha \theta A_{1}+(1-\alpha) \theta A_{2}\right)\right)\right] \operatorname{Var}\left(d_{t}\right) .
\end{aligned}
$$

Proof. See Appendix A.

As the definition, the bullwhip effect in the supply chain with two retailers by the MMSE method, denoted by $\mathrm{BWE}_{\mathrm{mmse}}$, is derived as

$$
\begin{aligned}
& \mathrm{BWE}_{\mathrm{mmse}}=\frac{\operatorname{Var}\left(q_{t}\right)}{\operatorname{Var}\left(d_{t}\right)}=\left(1+\alpha \phi A_{1}+(1-\alpha) \phi A_{2}\right)^{2} \\
&+\left(\alpha \phi A_{1}+(1-\alpha) \phi A_{2}\right)^{2}-2\left(1+\alpha \phi A_{1}+(1-\alpha)\right. \\
&\left.\cdot \phi A_{2}\right)\left(\alpha \phi A_{1}+(1-\alpha) \phi A_{2}\right) \frac{(\phi-\theta)(1-\phi \theta)}{1+\theta^{2}-2 \phi \theta}+2 \\
& \cdot \frac{1-\phi^{2}}{1+\theta^{2}-2 \phi \theta}\left(\left(\alpha \theta A_{1}+(1-\alpha) \theta A_{2}\right)^{2}\right. \\
&+\left(1+\alpha \phi A_{1}+(1-\alpha) \phi A_{2}\right)\left(\alpha \theta A_{1}+(1-\alpha) \theta A_{2}\right)
\end{aligned}
$$




$$
\begin{aligned}
& \cdot(\phi-\theta-1)-\left(\alpha \phi A_{1}+(1-\alpha) \phi A_{2}\right) \\
& \left.\cdot\left(\alpha \theta A_{1}+(1-\alpha) \theta A_{2}\right)\right)
\end{aligned}
$$

Now, we have the exact measure of bullwhip effect under the MMSE forecasting method.

3.2. Measure of the Bullwhip Effect under the MA Forecasting Method. Under the MA forecasting method, according to (9)-(10) and (19), the order of retailer 1 in period $t$ can be given as

$$
\begin{aligned}
q_{1, t}= & \widehat{D}_{1, t}^{L_{1}}-\widehat{D}_{1, t-1}^{L_{1}}+z\left(\widehat{\sigma}_{1, t}^{L_{1}}-\widehat{\sigma}_{1, t-1}^{L_{1}}\right)+d_{1, t-1} \\
= & \frac{L_{1}}{k} \sum_{i=1}^{k} d_{1, t-i}-\frac{L_{1}}{k} \sum_{i=1}^{k} d_{1, t-i-1}+d_{1, t-1} \\
& +z\left(\widehat{\sigma}_{1, t}^{L_{1}}-\widehat{\sigma}_{1, t-1}^{L_{1}}\right) .
\end{aligned}
$$

According to previous literature, $\widehat{\sigma}_{1, t}^{L_{1}}$ has no influence on the bullwhip effect. Similar to the minimum mean square error forecasting method, we have

$$
\begin{aligned}
q_{1, t} & =\left(1+\frac{L_{1}}{k}\right) d_{1, t-1}-\frac{L_{1}}{k} d_{1, t-k-1} \\
& =\alpha\left(1+\frac{L_{1}}{k}\right) d_{t-1}-\alpha \frac{L_{1}}{k} d_{t-k-1}
\end{aligned}
$$

According to the above calculation process, we can get the order quantity of retailer 2 in period $t$ similarly as follows:

$$
\begin{aligned}
q_{2, t} & =\left(1+\frac{L_{2}}{k}\right) d_{2, t-1}-\frac{L_{2}}{k} d_{2, t-k-1} \\
& =(1-\alpha)\left(1+\frac{L_{2}}{k}\right) d_{t-1}-(1-\alpha) \frac{L_{2}}{k} d_{t-k-1}
\end{aligned}
$$

Take the sum of orders for two retailers; the result can be written as

$$
\begin{aligned}
q_{t}= & \alpha\left(1+\frac{L_{1}}{k}\right) d_{t-1}-\alpha \frac{L_{1}}{k} d_{t-k-1} \\
& +(1-\alpha)\left(1+\frac{L_{2}}{k}\right) d_{t-1}-(1-\alpha) \frac{L_{2}}{k} d_{t-k-1} \\
= & \left(1+\alpha \frac{L_{1}}{k}+(1-\alpha) \frac{L_{2}}{k}\right) d_{t-1} \\
& -\left(\alpha \frac{L_{1}}{k}+(1-\alpha) \frac{L_{2}}{k}\right) d_{t-k-1} .
\end{aligned}
$$

Proposition 2. The variance of total order quantity of two retailers under the MA forecasting method in the period of $t$ can be determined as

$$
\operatorname{Var}\left(q_{t}\right)=\left[\begin{array}{c}
\left(1+\alpha \frac{L_{1}}{k}+(1-\alpha) \frac{L_{2}}{k}\right)^{2}+\left(\alpha \frac{L_{1}}{k}+(1-\alpha) \frac{L_{2}}{k}\right)^{2} \\
-2\left(1+\alpha \frac{L_{1}}{k}+(1-\alpha) \frac{L_{2}}{k}\right)\left(\alpha \frac{L_{1}}{k}+(1-\alpha) \frac{L_{2}}{k}\right) \phi^{k-1} \frac{(\phi-\theta)(1-\phi \theta)}{1+\theta^{2}-2 \phi \theta}
\end{array}\right] \operatorname{Var}\left(d_{t}\right) .
$$

Proof. See Appendix B.

Take the variance of total order $\operatorname{Var}\left(q_{t}\right)$ divided by $\operatorname{Var}\left(d_{t}\right)$; the bullwhip effect measure under the MA forecasting method, called $\mathrm{BWE}_{\mathrm{MA}}$, is given as

$$
\begin{aligned}
\mathrm{BWE}_{\mathrm{MA}}= & \left(1+\alpha \frac{L_{1}}{k}+(1-\alpha) \frac{L_{2}}{k}\right)^{2} \\
+ & \left(\alpha \frac{L_{1}}{k}+(1-\alpha) \frac{L_{2}}{k}\right)^{2} \\
- & 2\left(1+\alpha \frac{L_{1}}{k}+(1-\alpha) \frac{L_{2}}{k}\right) \\
& \cdot\left(\alpha \frac{L_{1}}{k}+(1-\alpha) \frac{L_{2}}{k}\right) \phi^{k-1} \\
& \cdot \frac{(\phi-\theta)(1-\phi \theta)}{1+\theta^{2}-2 \phi \theta} .
\end{aligned}
$$

3.3. Behavior of the Bullwhip Effect under the ES Forecasting Method. In this section, we use the exponential smoothing forecasting technique to perform demand forecast. According to Zhang [8], we know that the forecasting demand of retailer 1 in period $t$ is

$$
\widehat{d}_{1, t}=\sum_{i=0}^{\infty} \lambda_{1}\left(1-\lambda_{1}\right)^{i} d_{1, t-i-1},
$$

in which $\lambda_{1}$ is the smoothing exponent of retailer 1 .

Therefore, $\widehat{d}_{1, t}$ can be interpreted as the weighted average of all past demands of retailer 1 with exponentially declining weights. Then, $\tau$-period-ahead forecasting demand of retailer 1 under ES method simply extends the one-period-ahead forecast similar to the MA case where

$$
\widehat{d}_{1, t+\tau}=\widehat{d}_{1, t} . \quad \tau \geq 1 .
$$

Then, the forecast for the lead-time demand of retailer 1 can be expressed as

$$
\widehat{D}_{1, t}^{L_{1}}=L_{1} \widehat{d}_{1, t} .
$$


Using (20) and (38), we can have

$$
\widehat{D}_{1, t}^{L_{1}}-\widehat{D}_{1, t-1}^{L_{1}}=\lambda_{1} L_{1}\left(d_{1, t-1}-\widehat{d}_{1, t-1}\right) .
$$

Thus, in the condition of order-up-to policy, the order quantity of retailer $1, q_{1, t}$, is

$$
\begin{aligned}
q_{1, t} & =\widehat{D}_{1, t}^{L_{1}}-\widehat{D}_{1, t-1}^{L_{1}}+z\left(\widehat{\sigma}_{1, t}^{L_{1}}-\widehat{\sigma}_{1, t-1}^{L_{1}}\right)+d_{1, t-1} \\
& =\lambda_{1} L_{1}\left(d_{1 . t-1}-\widehat{d}_{1, t-1}\right)+d_{1 . t-1} \\
& =\alpha d_{t-1}+\lambda_{1} L_{1}\left(\alpha d_{t-1}-\widehat{d}_{1, t-1}\right) .
\end{aligned}
$$

Here, there is also $\widehat{\sigma}_{1, t}^{L_{1}}=\widehat{\sigma}_{1, t-1}^{L_{1}}$ and $d_{1, t}=\alpha d_{t}$.

Retailer 2 conducts a similar behavior to retailer 1 , so we can get

$$
\begin{aligned}
q_{2, t} & =\lambda_{2} L_{2}\left(d_{2, t-1}-\widehat{d}_{2, t-1}\right)+d_{2 . t-1} \\
& =(1-\alpha) d_{t-1}+\lambda_{2} L_{2}\left((1-\alpha) d_{t-1}-\widehat{d}_{2, t-1}\right) .
\end{aligned}
$$

Take the sum of (40) and (41); the total order quantity is

$$
\begin{aligned}
q_{t}= & \alpha d_{t-1}+\lambda_{1} L_{1}\left(\alpha d_{t-1}-\widehat{d}_{1, t-1}\right)+(1-\alpha) d_{t-1} \\
& +\lambda_{2} L_{2}\left((1-\alpha) d_{t-1}-\widehat{d}_{2, t-1}\right) \\
= & \left(1+\alpha \lambda_{1} L_{1}+(1-\alpha) \lambda_{2} L_{2}\right) d_{t-1}-\lambda_{1} L_{1} \widehat{d}_{1, t-1} \\
& -\lambda_{2} L_{2} \widehat{d}_{2, t-1} .
\end{aligned}
$$

Proposition 3. The variance of total order quantity with two retailers under the ES forecasting method in the period of $t$ can be given as

$$
\begin{aligned}
& \operatorname{Var}\left(q_{t}\right)=\operatorname{Var}\left(d_{t}\right)\left[\left(1+\alpha \lambda_{1} L_{1}+(1-\alpha) \lambda_{2} L_{2}\right)^{2}\right. \\
& +\frac{L_{1}^{2} \lambda_{1}^{3} \alpha^{2}}{2-\lambda_{1}}\left(1+\frac{2\left(1-\lambda_{1}\right)}{1-\left(1-\lambda_{1}\right) \phi} \frac{(\phi-\theta)(1-\phi \theta)}{\left(1+\theta^{2}-2 \phi \theta\right)}\right) \\
& +\frac{L_{2}^{2} \lambda_{2}^{3}(1-\alpha)^{2}}{2-\lambda_{2}}\left(1+\frac{2\left(1-\lambda_{2}\right)}{1-\left(1-\lambda_{2}\right) \phi} \frac{(\phi-\theta)(1-\phi \theta)}{\left(1+\theta^{2}-2 \phi \theta\right)}\right) \\
& -2\left(1+\alpha \lambda_{1} L_{1}+(1-\alpha) \lambda_{2} L_{2}\right) \\
& +\frac{(\phi-\theta)(1-\phi \theta)}{1+\theta^{2}-2 \phi \theta}\left(\frac{\alpha L_{1} \lambda_{1}^{2}}{1-\left(1-\lambda_{1}\right) \phi}+\frac{(1-\alpha) L_{2} \lambda_{2}^{2}}{1-\left(1-\lambda_{2}\right) \phi}\right) \\
& +2 \lambda_{1}^{2} \lambda_{2}^{2} L_{1} L_{2} \alpha(1-\alpha)\left(\frac{(\phi-\theta)(1-\phi \theta)}{1+\theta^{2}-2 \phi \theta}\right. \\
& +\frac{1}{\left(\phi+\lambda_{2}-1\right)\left(1-\left(1-\lambda_{1}\right) \phi\right)} \\
& +\frac{1}{1-\left(1-\lambda_{1}\right)\left(1-\lambda_{2}\right)}(1 \\
& \left.\left.\left.+\frac{(\phi-\theta)(1-\phi \theta)}{1+\theta^{2}-2 \phi \theta}\left(\frac{1-\lambda_{2}}{1-\left(1-\lambda_{2}\right) \phi}-\frac{1}{\phi+\lambda_{2}-1}\right)\right)\right)\right]
\end{aligned}
$$

Proof. See Appendix C.
According to the most widely used method, the expression of bullwhip effect under the ES forecasting technique is as follows, named $\mathrm{BWE}_{\mathrm{ES}}$, which seems relatively complicated:

$$
\begin{aligned}
& \mathrm{BWE}_{\mathrm{ES}}=\left(1+\alpha \lambda_{1} L_{1}+(1-\alpha) \lambda_{2} L_{2}\right)^{2}+\frac{L_{1}^{2} \lambda_{1}^{3} \alpha^{2}}{2-\lambda_{1}}(1 \\
& \left.+\frac{2\left(1-\lambda_{1}\right)}{1-\left(1-\lambda_{1}\right) \phi} \frac{(\phi-\theta)(1-\phi \theta)}{\left(1+\theta^{2}-2 \phi \theta\right)}\right) \\
& +\frac{L_{2}^{2} \lambda_{2}^{3}(1-\alpha)^{2}}{2-\lambda_{2}}\left(1+\frac{2\left(1-\lambda_{2}\right)}{1-\left(1-\lambda_{2}\right) \phi}\right. \\
& \left.\cdot \frac{(\phi-\theta)(1-\phi \theta)}{\left(1+\theta^{2}-2 \phi \theta\right)}\right)-2\left(1+\alpha \lambda_{1} L_{1}+(1-\alpha)\right. \\
& \left.\cdot \lambda_{2} L_{2}\right) \frac{(\phi-\theta)(1-\phi \theta)}{1+\theta^{2}-2 \phi \theta}\left(\frac{\alpha L_{1} \lambda_{1}^{2}}{1-\left(1-\lambda_{1}\right) \phi}\right. \\
& \left.+\frac{(1-\alpha) L_{2} \lambda_{2}^{2}}{1-\left(1-\lambda_{2}\right) \phi}\right)+2 \lambda_{1}^{2} \lambda_{2}^{2} L_{1} L_{2} \alpha(1-\alpha) \\
& \cdot\left[\frac{(\phi-\theta)(1-\phi \theta)}{1+\theta^{2}-2 \phi \theta} \frac{1}{\left(\phi+\lambda_{2}-1\right)\left(1-\left(1-\lambda_{1}\right) \phi\right)}\right. \\
& +\frac{1}{1-\left(1-\lambda_{1}\right)\left(1-\lambda_{2}\right)}(1 \\
& +\frac{(\phi-\theta)(1-\phi \theta)}{1+\theta^{2}-2 \phi \theta}\left(\frac{1-\lambda_{2}}{1-\left(1-\lambda_{2}\right) \phi}\right. \\
& \left.\left.\left.-\frac{1}{\phi+\lambda_{2}-1}\right)\right)\right] \text {. }
\end{aligned}
$$

\section{Behavior and Comparison of Bullwhip Effect by Three Forecasting Methods}

4.1. Behavior of the Bullwhip Effect and Parameter Analysis for the MMSE. We will explore and illustrate the impact of various parameters on the bullwhip effect by using the numerical experiments.

According to Duc et al. [12], we know that the bullwhip effect occurs only if $0<\phi<1$ under the MMSE forecasting method. So, next, we will study the behavior of the bullwhip effect only when $0<\phi<1$.

There are three cases that we should consider.

Case 1 ( $\alpha=0$ or $\alpha=1)$. In this case, the supply chain only has one retailer and one manufacturer; thus, the behaviors of the bullwhip effect have been studied by Duc et al. [16].

Case $2\left(L_{1}=L_{2}=L\right)$. When the lead times of the retailer are the same, the market share $\alpha$ has no influence on the bullwhip effect. Therefore, the behavior of the bullwhip effect in the supply chain of our paper is the same as that in the supply chain with one retailer and one manufacturer. This result can be shown in the next expression by $\mathrm{BWE}_{\mathrm{mmse}}$. 


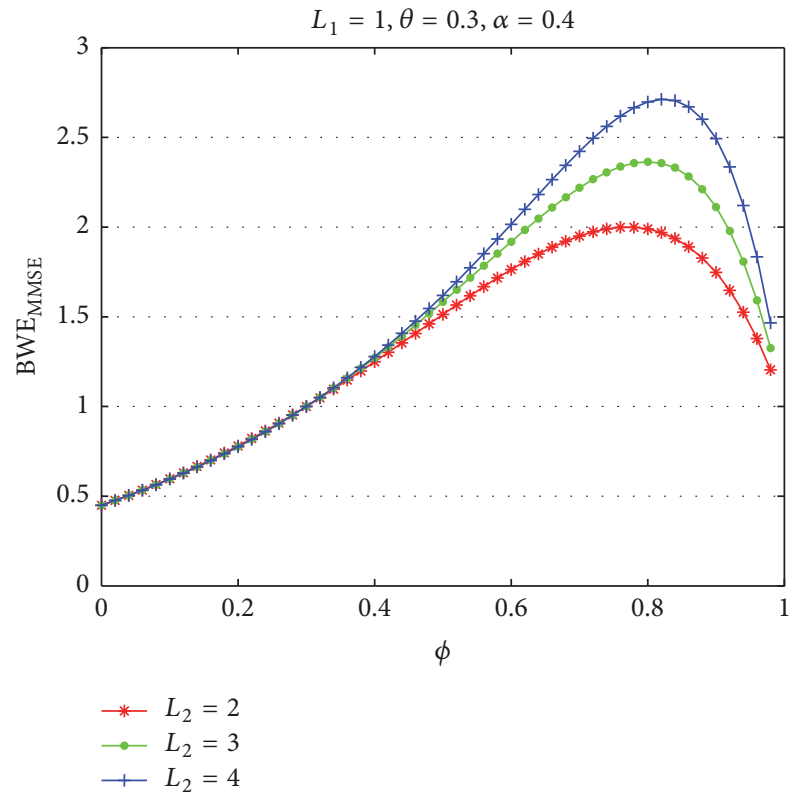

(a)

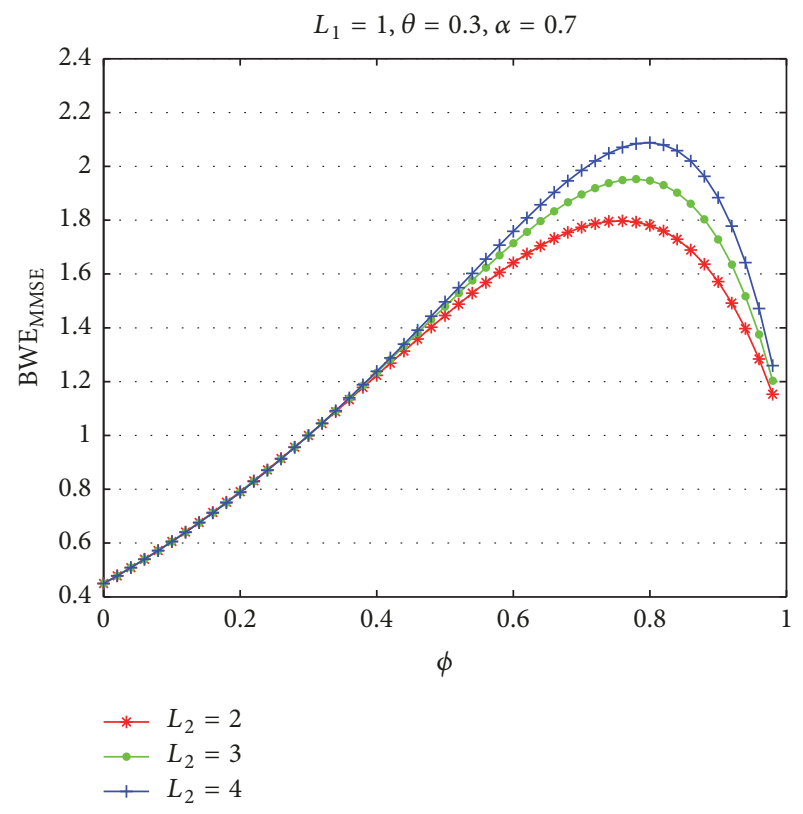

(b)

FIgURE 2: Effect of $\phi$ on BWE $\mathrm{Bmme}_{\text {me }}$ in the case of $L_{1}=1, \alpha=0.4$ and 0.7.

TABLE 1: Values of bullwhip effect under MMSE in the case of $L_{1}=1$ and $\alpha=0.4$.

\begin{tabular}{|c|c|c|c|c|c|c|c|c|c|c|}
\hline \multirow{2}{*}{$L_{2}$} & \multicolumn{9}{|c|}{$\phi$} & \multirow{2}{*}{$\phi_{\max }$} \\
\hline & 0.1 & 0.2 & 0.3 & 0.4 & 0.5 & 0.6 & 0.7 & 0.8 & 0.9 & \\
\hline 2 & 0.5969 & 0.7805 & 1.0000 & 1.2493 & 1.5134 & 1.7637 & 1.9502 & 1.9899 & 1.7473 & 0.771 \\
\hline 3 & 0.5951 & 0.7763 & 1.0000 & 1.2704 & 1.5837 & 1.9186 & 2.2191 & 2.3641 & 2.1120 & 0.800 \\
\hline 4 & 0.5949 & 0.7754 & 1.0000 & 1.2789 & 1.6197 & 2.0159 & 2.4221 & 2.6982 & 2.4931 & 0.824 \\
\hline
\end{tabular}

TABLE 2: Values of bullwhip effect under MMSE in the case of $L_{1}=1$ and $\alpha=0.7$.

\begin{tabular}{|c|c|c|c|c|c|c|c|c|c|c|}
\hline \multirow{2}{*}{$L_{2}$} & \multicolumn{9}{|c|}{$\phi$} & \multirow{2}{*}{$\phi_{\max }$} \\
\hline & 0.1 & 0.2 & 0.3 & 0.4 & 0.5 & 0.6 & 0.7 & 0.8 & 0.9 & \\
\hline 2 & 0.6062 & 0.7912 & 1.0000 & 1.2233 & 1.4454 & 1.6417 & 1.7732 & 1.7806 & 1.5714 & 0.757 \\
\hline 3 & 0.6052 & 0.7891 & 1.0000 & 1.2336 & 1.4791 & 1.7141 & 1.8958 & 1.9465 & 1.7288 & 0.778 \\
\hline 4 & 0.6051 & 0.7887 & 1.0000 & 1.2378 & 1.4962 & 1.7587 & 1.9852 & 2.0880 & 1.8837 & 0.797 \\
\hline
\end{tabular}

Under the condition of $L_{1}=L_{2}=L$, we have $A_{1}=A_{2}=$ $A=\left(1-\phi^{L}\right) /(1-\phi)$; then, the bullwhip effect can be written as

$$
\begin{gathered}
\mathrm{BWE}_{\text {mmse }}=(1+\phi A)^{2}+(\phi A)^{2}-2 \phi A(1+\phi A) \\
. \frac{(\phi-\theta)(1-\phi \theta)}{1+\theta^{2}-2 \phi \theta}+2 \frac{1-\phi^{2}}{\left(1+\theta^{2}-2 \phi \theta\right)}\left((\theta A)^{2}\right. \\
\left.+(1+\phi A)(\theta A)(\phi-\theta-1)-\phi \theta A^{2}\right) .
\end{gathered}
$$

Case $3\left(\alpha \neq 0, \alpha \neq 1\right.$, and $\left.L_{1} \neq L_{2}\right)$. In this case, we take a simulation for $\mathrm{BWE}_{\mathrm{mmse}}$ at the range of $\phi>0$ in order to see the impact of different parameters on the BWE. We perform a series of numerical experiments for different values of $L_{1}$, $L_{2}, \phi, \theta$, and $\alpha$, and the results are shown in the following.
Figure 2 depicts the impact of $\phi$ on the bullwhip effect when the other parameters are fixed. The bullwhip effect measure first increases and then decreases along with the increasing of $\phi$.

From Tables 1 and 2 , for given values of $L_{1}, L_{2}, \theta$, and $\alpha$, it can be seen that the bullwhip effect reaches the maximum at a certain value of $\phi$, which is here denoted as $\phi_{\max }$. Moreover, according to Tables $1-4$, it is discovered that the bullwhip effect exists if and only if $\phi>0.3$ for any values of $L_{1}, L_{2}, \theta$, and $\alpha$. The results show that as the value of $L_{2}$ increases, the bullwhip effect BWE $\mathrm{Emse}_{\text {me }}$ becomes larger when the bullwhip effect $\mathrm{BWE}_{\text {mmse }}>1$; that is, the value of $\phi>0.3$, and $\phi_{\max }$ also increases. When the $\phi$ value is smaller than 0.3 , the bullwhip effect has the opposite trend on the change of $L_{2}$. In addition, compared with data between Tables 1 and 2, it is shown that as the market share $\alpha$ increases, both the bullwhip effect and 
TABLE 3: Values of bullwhip effect under MMSE in the case of $L_{2}=1$ and $\alpha=0.4$.

\begin{tabular}{ccccccccccc}
\hline$L_{1}$ & & & \multicolumn{9}{c}{$\phi$} & & & & \\
& 0.1 & 0.2 & 0.3 & 0.4 & 0.5 & 0.6 & 0.7 & 0.8 & 0.9 \\
\hline 2 & 0.6031 & 0.7877 & 1.0000 & 1.2319 & 1.4678 & 1.6816 & 1.8308 & 1.8483 & 1.6279 & 0.762 \\
3 & 0.6018 & 0.7848 & 1.0000 & 1.2458 & 1.5134 & 1.7804 & 1.9995 & 2.0789 & 1.8489 & 0.787 \\
4 & 0.6017 & 0.7842 & 1.0000 & 1.2514 & 1.5366 & 1.8417 & 2.1241 & 2.2789 & 2.0713 & 0.808 \\
\hline
\end{tabular}

TABLE 4: Values of bullwhip effect under MMSE in the case of $L_{2}=1$ and $\alpha=0.7$.

\begin{tabular}{|c|c|c|c|c|c|c|c|c|c|c|}
\hline \multirow{2}{*}{$L_{1}$} & \multicolumn{9}{|c|}{$\phi$} & \multirow{2}{*}{$\phi_{\max }$} \\
\hline & 0.1 & 0.2 & 0.3 & 0.4 & 0.5 & 0.6 & 0.7 & 0.8 & 0.9 & \\
\hline 2 & 0.5939 & 0.7770 & 1.0000 & 1.2580 & 1.5366 & 1.8058 & 2.0120 & 2.0639 & 1.8101 & 0.775 \\
\hline 3 & 0.5917 & 0.7720 & 1.0000 & 1.2828 & 1.6197 & 1.9903 & 2.3350 & 2.5169 & 2.2550 & 0.805 \\
\hline 4 & 0.5915 & 0.7711 & 1.0000 & 1.2928 & 1.6623 & 2.1071 & 2.5812 & 2.9266 & 2.7274 & 0.829 \\
\hline
\end{tabular}

$\phi_{\max }$ decrease, at the fixed values of $\phi, L_{1}$, and $L_{2}$, which meets the condition of $L_{1}<L_{2}$.

Tables 3-4 and Figure 3 have a similar trend to Tables 1 and 2 and Figure 2. We set $L_{1}>L_{2}$ in this part of simulations. Figure 3 illustrates the behavior of $\mathrm{BWE}_{\mathrm{mmse}}$ with respect to $\phi$ for fixed $L_{1}, L_{2}, \theta$, and $\alpha$. First, it is shown that the bullwhip effect increases to a maximum and then drops as the autoregressive coefficient increases from 0 to 1 . The bullwhip effect under the MMSE forecasting method is less than 1 ; that is, there is no bullwhip effect in the supply chain while $\phi<$ 0.3 . Second, when $L_{1}$ increases and $L_{2}, \theta$, and $\alpha$ are at certain values, the bullwhip effect under MMSE method increases, and $\phi_{\max }$ also rises for $\phi>0.3$. Moreover, when $\alpha$ increases for fixed $L_{1}, L_{2}, \theta$, and $\phi$ under the condition of $L_{1}>$ $L_{2}$, on the contrary, the bullwhip effect increases and $\phi_{\max }$ rises.

In a word, these results can be seen clearly from data of Tables 1-4. In conclusion, the market share of the retailer which has a longer lead time affects the bullwhip effect more significantly. From our research, we discover that the larger the market share of the retailer with a long lead time is, the greater the bullwhip effect is.

Next, Figure 4 shows how the market share $\alpha$ affects bullwhip effect in two cases. Further, the bullwhip effect is the linear correlation with $\alpha$. When $\alpha$ goes up, the bullwhip effect drops in Figure 4(a) for the condition of $L_{1}<L_{2}$. However, when $\alpha$ goes up, the bullwhip effect changes conversely in Figure 4(b) for the case of $L_{1}>L_{2}$. Both figures indicate that larger lead time can result in a greater bullwhip effect. When $L_{1}>L_{2}$, the increasing of $\alpha$ means more demand needs to be forecasted in longer lead time. Thus, the lead time is critical to the bullwhip effect.

In the simulation, the first-order moving average coefficient $\theta$ affects the bullwhip effect in a way that, along with the increase of $\theta$ from -1 to 1 , the bullwhip effect first increases slowly to the maximum where it corresponds to the value $\theta_{\max }$ and then decreases quickly in Figure 5. From the figure, it is observed that when $\theta$ is almost larger than 0.6 , the bullwhip effect does not exist. Moreover, the increasing of $L_{2}$ can lead to the increasing of bullwhip effect as well as $\theta_{\max }$ under the existence of the bullwhip effect. So, Figure 8 shows that we can enlarge $\theta$ to reduce the bullwhip effect appropriately when other parameters are already determined.

4.2. Behavior of the Bullwhip Effect and Parameter Analysis for the MA. Similar to Section 4.1, there are also three cases that we should consider. However, there is one difference of simulation: that we need to consider the whole range of $\phi$ from -1 to 1 in this part.

Case $1(\alpha=0$ or $\alpha=1)$. When the market share of retailer is zero or one, it means there is only one retailer in the supply chain. We do not study this case in our paper.

Case $2\left(L_{1}=L_{2}=L\right)$. In the case of $L_{1}=L_{2}=L$, (35) can be written by simplification as

$$
\begin{aligned}
\mathrm{BWE}_{\mathrm{MA}}= & \left(1+\frac{L}{k}\right)^{2}+\left(\frac{L}{k}\right)^{2} \\
& -2 \frac{L}{k}\left(1+\frac{L}{k}\right) \phi^{k-1} \frac{(\phi-\theta)(1-\phi \theta)}{1+\theta^{2}-2 \phi \theta} .
\end{aligned}
$$

The bullwhip effect has no effect with the market share $\alpha$ from (46).

Case $3\left(\alpha \neq 0, \alpha \neq 1\right.$, and $\left.L_{1} \neq L_{2}\right)$. When we set $\alpha \neq 0$, $\alpha \neq 1$, and $L_{1} \neq L_{2}$, we know the market share will affect the bullwhip effect. Next, it is studied how the parameters influence the bullwhip effect under the MA forecasting technique by simulations on the base of the expression of (35).

As shown in Figure 6, the bullwhip effect varies differently with respect to the first autoregressive coefficient under the different value of $k$. In this figure, we fix the values of $L_{1}=1$, $\theta=0.3$, and $\alpha=0.4$ and run a function of $\phi$ for $L_{2}=2,3$, and 4 , with $k=4$ and 5 . The bullwhip effect first increases to the maximum and then decreases quickly with the increasing of $\phi$ for even $k$. When $\phi=-1$ or $\phi=1$, the values of the bullwhip effect are both one. Likewise, for odd $k$, the bullwhip effect first quickly decreases to a stable value and then also decreases with the continuous increase of $\phi$. When $\phi$ is near negative one, the bullwhip effect is most pronounced. 


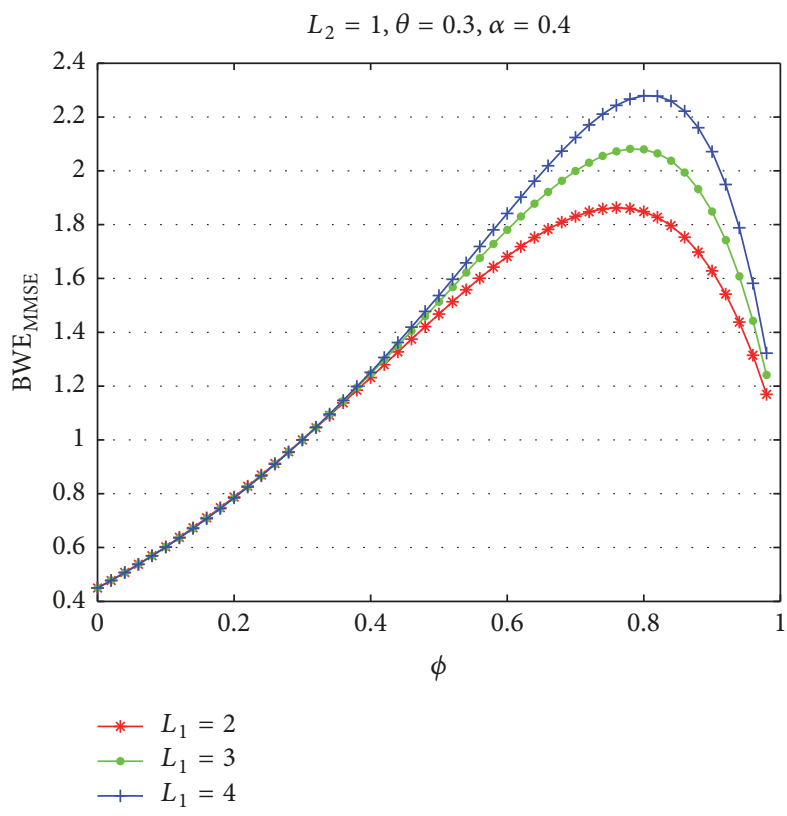

(a)

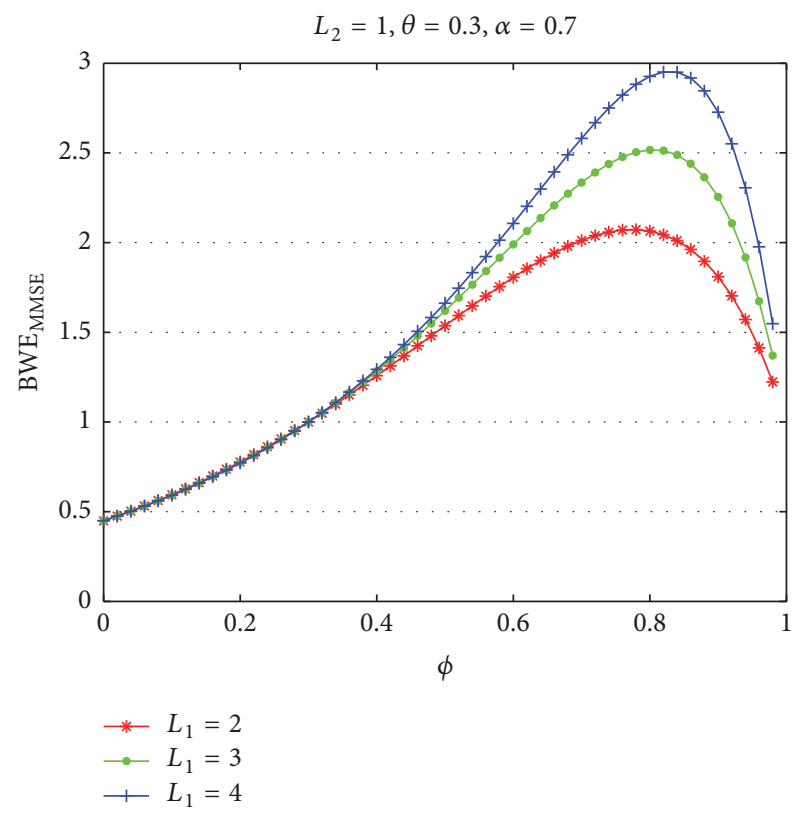

(b)

Figure 3: Effect of $\phi$ on BWE $\mathrm{Bmme}_{\text {me }}$ in the case of $L_{2}=1, \alpha=0.4$ and 0.7.

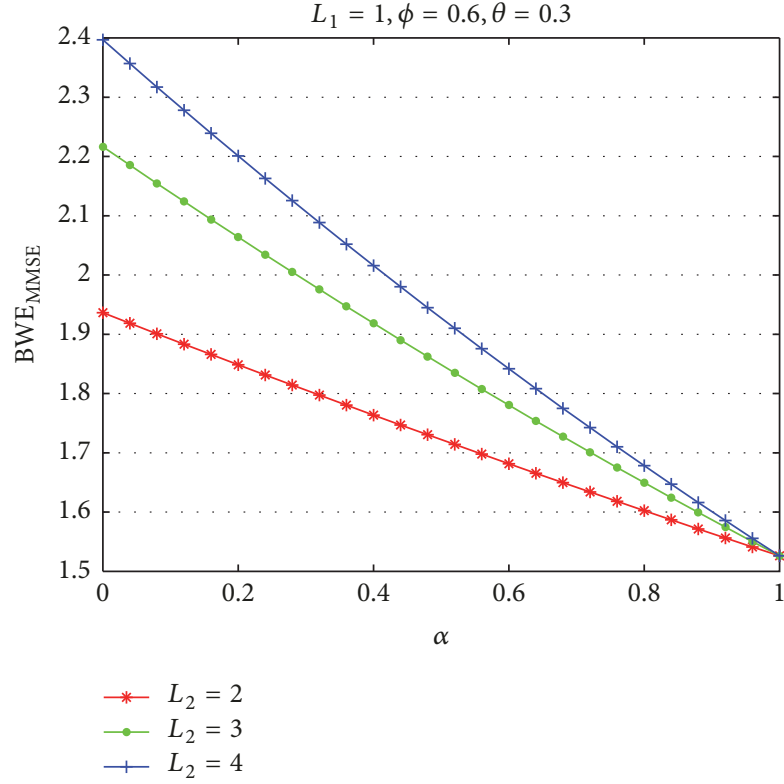

(a)

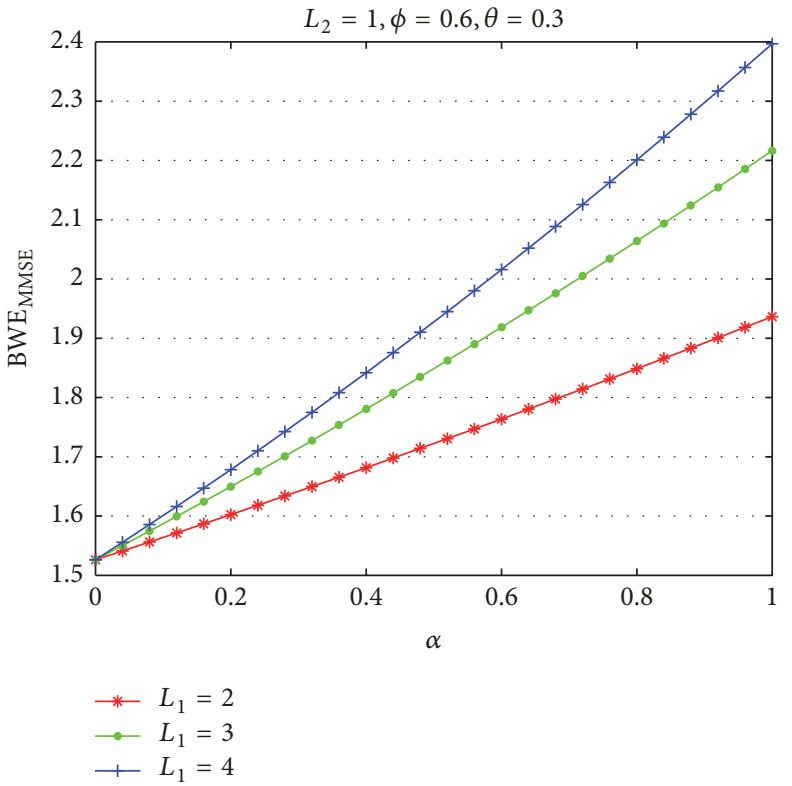

(b)

FIGURE 4: The bullwhip effect corresponding to $\alpha$ under the MMSE in case of $L_{1}<L_{2}$.

Moreover, $\mathrm{BWE}_{\mathrm{MA}}$ is a function of $L_{2}$ and increases as the lead time $L_{2}$ increases. Equation (36) shows that the behavior of $L_{1}$ is the same as $L_{1}$. So, the bullwhip effect increases unconditionally with the increasing of the lead time.

Figure 7(a) mainly depicts the influence of market share on the bullwhip effect. We set $L_{1}<L_{2}$ in Figure 7(a) and $L_{1}>L_{2}$ in Figure 7(b) when other parameters are fixed. Figure 7(a) shows that the bullwhip effect decreases as the market share $\alpha$ increases. And, however, Figure 7(b) shows that the bullwhip effect increases as the market share $\alpha$ increases. In a word, when the market share of the retailer which has a longer lead time increases, the bullwhip effect increases too.

From the two figures, we also observe that the bullwhip effect under the MA forecasting method is approximately symmetrical about $\phi$ when the span $k$ is even.

The first-order moving average coefficient $\theta$ has a simple relationship with the bullwhip effect. In Figure 8, the larger 


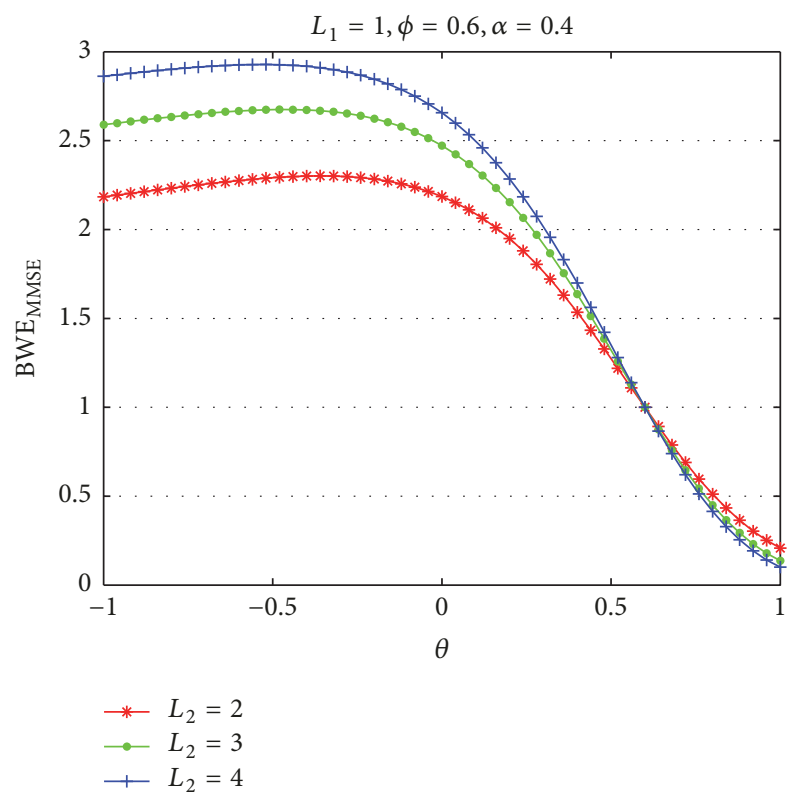

FIGURE 5: Effect of $\theta$ on the bullwhip effect under the MMSE method for different $\alpha$.

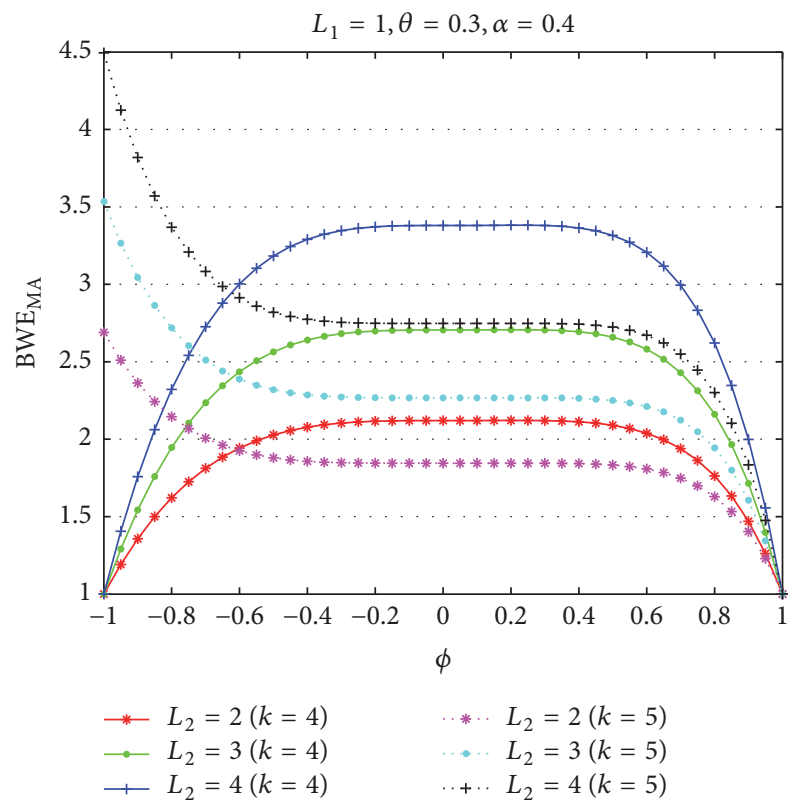

Figure 6: Effect of $\phi$ on the bullwhip effect under the MA method for different $L_{2}$ and $k$.

the value of $\theta$ from -1 to 1 , the greater the bullwhip effect. So, in the supply chain, we can reduce $\theta$ to decrease the bullwhip effect. The span $k$ is negative with the bullwhip effect, and the increasing of $k$ can reduce $\mathrm{BWE}_{\mathrm{MA}}$.

4.3. Behavior of the Bullwhip Effect and Parameter Analysis for the ES. Based on the analytical expression of $\mathrm{BWE}_{\mathrm{ES}}$, there are also three cases that we should consider similar to the MMSE and MA methods.

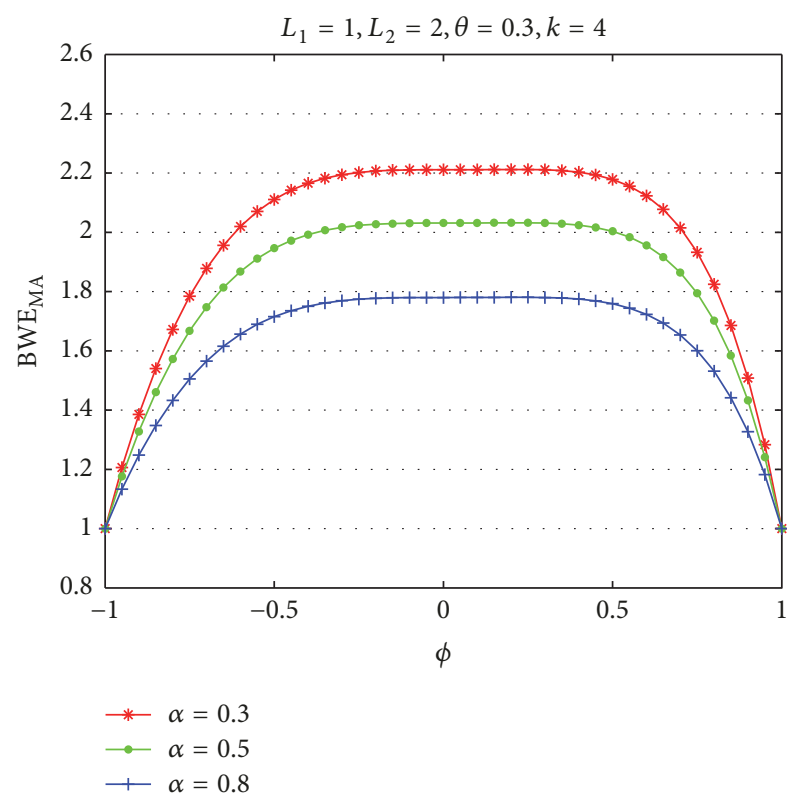

(a)

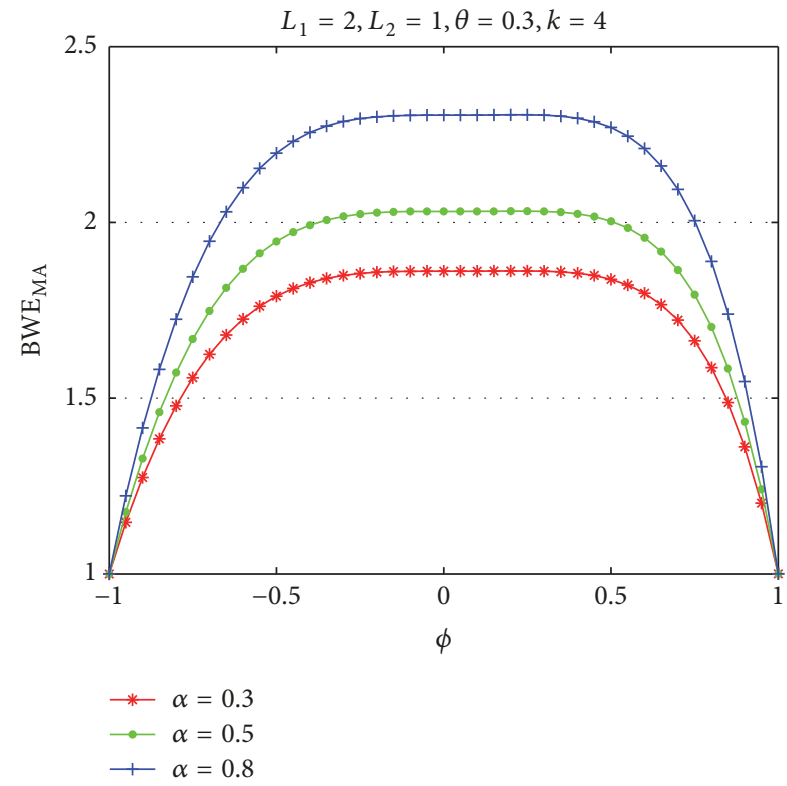

(b)

FIgURE 7: Effect of $\phi$ on the bullwhip effect for different $\alpha$ under $L_{1}<L_{2}$ and $L_{1}>L_{2}$.

Case $1(\alpha=0$ or $\alpha=1)$. Here, the conclusion is identical to the cases of MMSE and MA method.

Case $2\left(L_{1}=L_{2}=L\right.$, and $\left.\lambda_{1}=\lambda_{2}=\lambda\right)$. We set two retailers having the same smoothing exponent; then, when $L_{1}=L_{2}=$ $L$, the market share $\alpha$ has no influence on the bullwhip effect.

Case $3\left(\alpha \neq 0, \alpha \neq 1\right.$, and $L_{1} \neq L_{2}$ or $\left.\lambda_{1} \neq \lambda_{2}\right)$. In order to discuss the impact of market share $\alpha$ on the bullwhip effect, we make the specific rules as $L_{1} \neq L_{2}$ and $\lambda_{1} \neq \lambda_{2}$. By numerical simulations, we will study the changes of $\mathrm{BWE}_{\mathrm{ES}}$. 


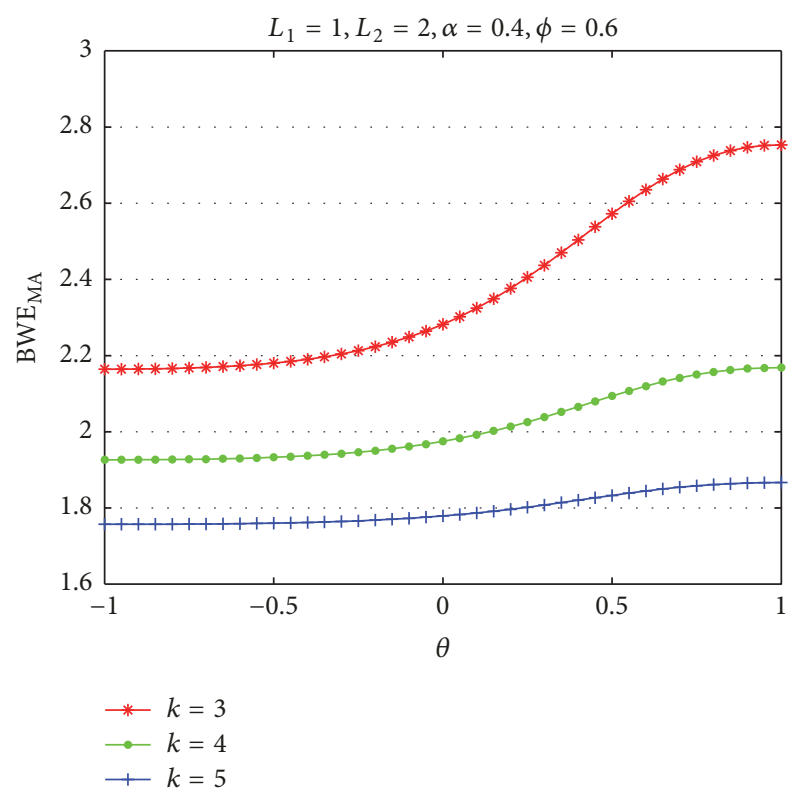

FIGURE 8: Effect of $\theta$ on the bullwhip effect for different span $k$.

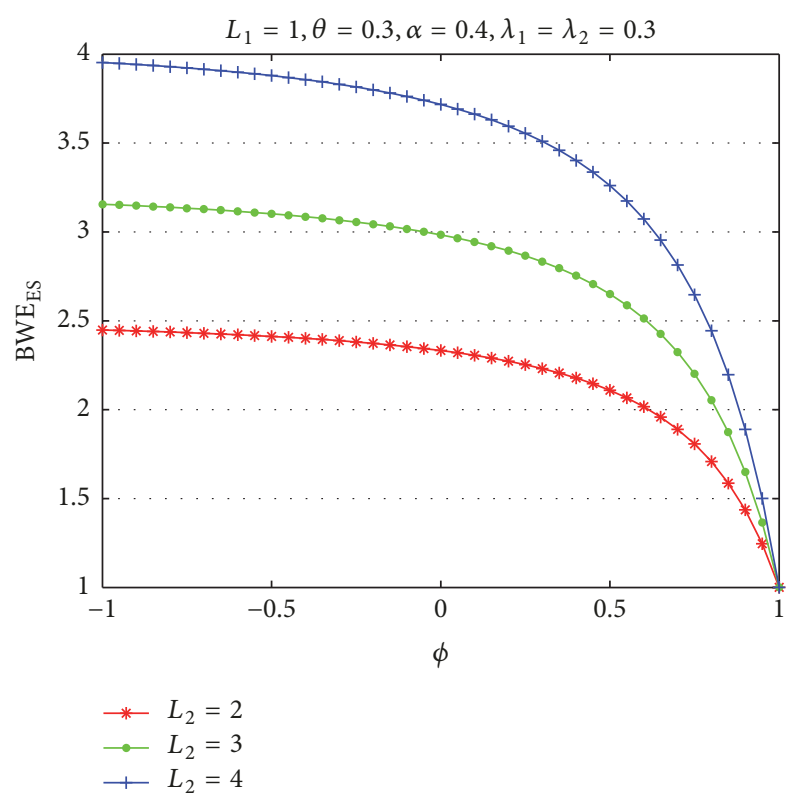

FIGURE 9: The impact of $\phi$ on $\mathrm{BWE}_{\mathrm{ES}}$ by varying $L_{2}$.

Figure 9 shows the trend of bullwhip effect along with the varying of $\phi$ from -1 to 1 under different values of $L_{2}$. $\mathrm{BWE}_{\mathrm{ES}}$ is decreased when $\phi$ increases and is increased when $L_{2}$ increases from 2 to 4 . In the supply chain, the longer the lead time is, the more difficult the forecast to the demand is. So, the bullwhip effect is larger and larger when the lead time of retailer 2 is increasing.

Figure 10 depicts how the bullwhip effect is affected by the market share under the different conditions of the lead time. A similar trend can be observed to Figure 10 where the bullwhip effect decreases when $\phi$ increases while $L_{1}, L_{2}, \theta, \alpha$, $\lambda_{1}$, and $\lambda_{2}$ are fixed.

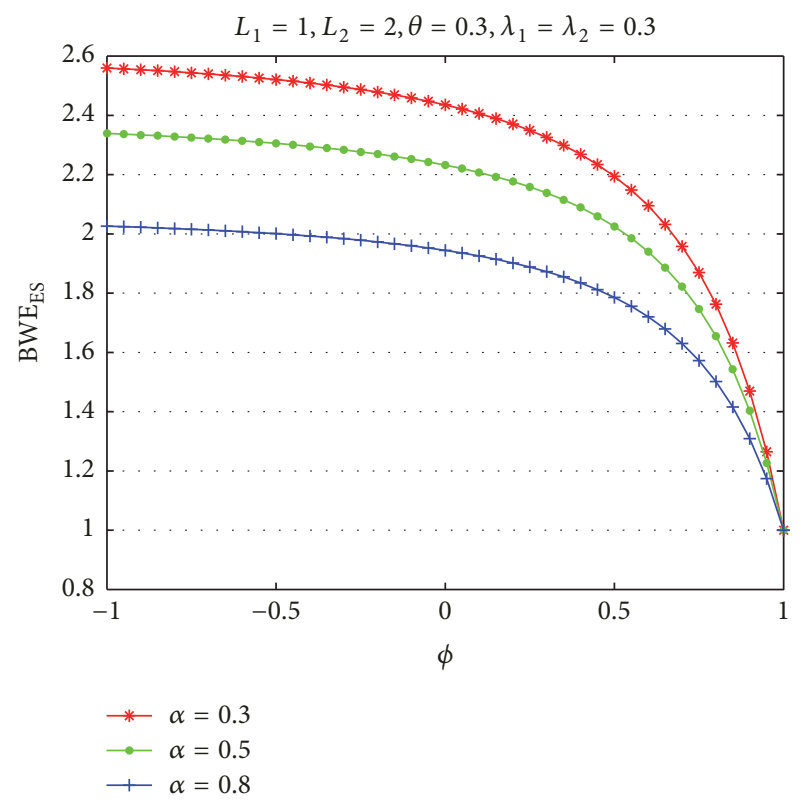

(a)

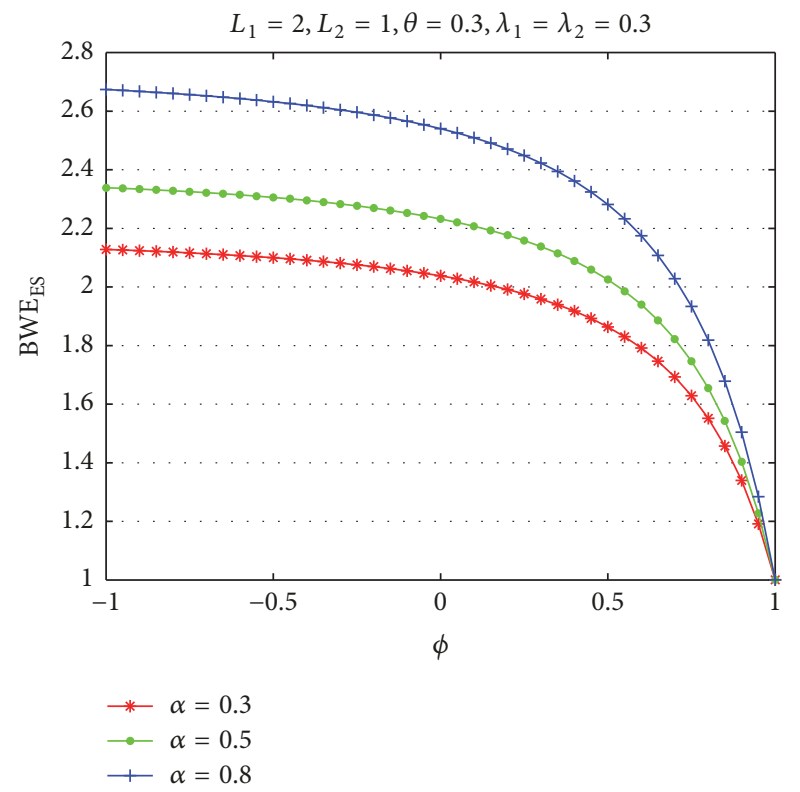

(b)

FIgURE 10: The impact of $\phi$ and $\alpha$ on the bullwhip effect on the condition of $L_{1}<L_{2}$ and $L_{1}>L_{2}$.

Moreover, when the values of $\lambda_{1}, \lambda_{2}, \theta, L_{1}$, and $L_{2}$ are fixed such that $L_{1}<L_{2}$, the bullwhip effect decreases as $\alpha$ increases. Under the fixed values of $\lambda_{1}, \lambda_{2}, \theta, L_{1}$, and $L_{2}$ such that $L_{1}>L_{2}$, yet, the bullwhip effect increases as $\alpha$ increases. This consequence can be observed from Figure 11(a) for the case $L_{1}<L_{2}$ and from Figure 10(b) for the case $L_{1}>L_{2}$.

In conclusion, when all other parameters are fixed, the bullwhip effect decreases as the market share of the retailer with a shorter lead time increases.

Figure 11(a) studies the influence of $\lambda_{1}$ on the bullwhip effect; it is indicated that $\mathrm{BWE}_{\mathrm{ES}}$ has a positive correlation with the smoothing coefficient of retailer 1 . In addition, the 


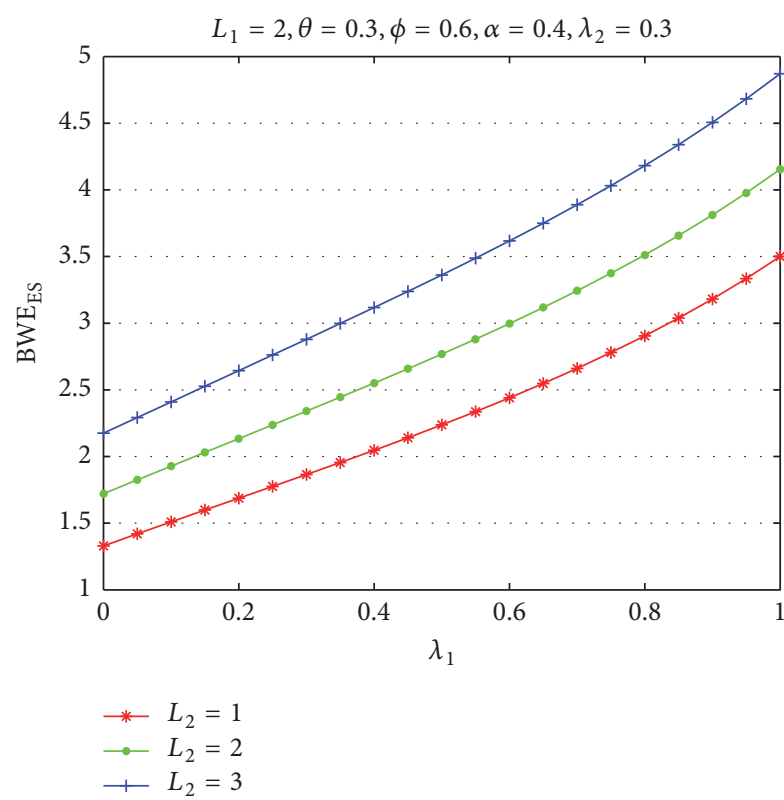

(a)

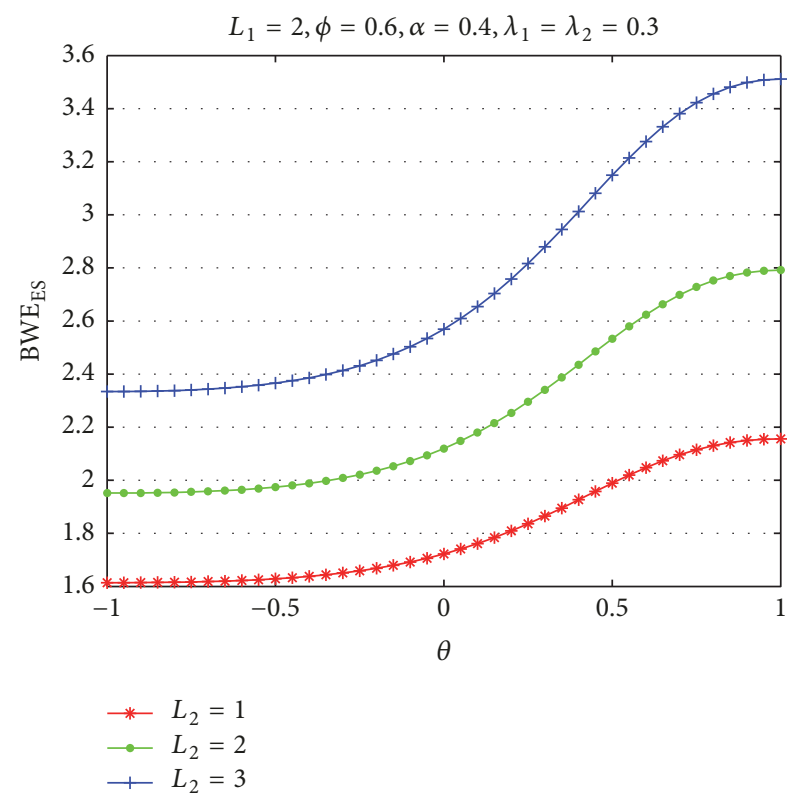

(b)

FIGURE 11: The impact of the smoothing coefficient $\lambda_{1}$ and $\theta$ on BWE $\mathrm{ES}_{\mathrm{ES}}$ for different $L_{2}$.

trend of BWE $\mathrm{ES}_{\mathrm{ES}}$ is roughly the same for different $L_{2}$. That is, the influence of the smoothing coefficient $\lambda_{1}$ on the bullwhip effect is determinate regardless of the measurement of $L_{1}$ and $L_{2}$.

Figure 11(b) indicates the behavior of the bullwhip effect with regard to $\theta$ for fixed values of other parameters. The bullwhip effect is increased slowly along with the increasing of $\theta$ from -1 to 0 ; however, it increases quickly when $\theta$ increases from 0 to 1 . Some other information can be discovered from Figure 11(b). The larger the value of $L_{2}$ is, the faster the bullwhip effect increases as $\theta$ increases.

\subsection{Comparison of the Bullwhip Effect by Three Forecasting} Methods. We study the bullwhip effect using three forecasting methods in Sections of 4.1-4.3. Next, we will compare the different influences of MMSE, MA, and ES on the bullwhip effect. For the comparability of the MA and ES methods, we set a constraint on the span $k$ of MA and the smoothing factors $\lambda_{1}$ and $\lambda_{2}$. According to Zhang [8], we obtain that the smoothing exponents are fixed as $\lambda_{1}=\lambda_{2}=2 /(k+1)$. This means the average data ages are the same for the MA and ES forecasting method. Further, we know $\phi+\lambda_{2}-1 \neq 0$ from the expression of the bullwhip effect (see (46)) under the ES forecasting method.

Figure 12 depicts the difference of the three forecasting methods on measuring the bullwhip effect by varying $\phi$ for different $k$ and $\lambda$. We observe that the bullwhip effect measure of MA is always smaller than that of ES no matter what $\phi$ is as long as $\lambda_{1}=\lambda_{2}=2 /(k+1)$. It can be seen that the bullwhip effect under the MMSE forecasting method does not exist when $\phi \leq 0.3$ from the two figures. The bullwhip effect for the three forecasting methods converges to one as $\phi$ approaches one.
Moreover, for fixed values of $\alpha, \theta, L_{1}$, and $L_{2}$, BWE $\mathrm{MMSE}_{\mathrm{MM}}$ is the least when $\phi$ is smaller than a certain value, called $\phi_{1}$. After $\phi$ becomes larger than $\phi_{1}$ and smaller than another certain value, called $\phi_{2}, \mathrm{BWE}_{\mathrm{MA}}$ is the smallest and $\mathrm{BWE}_{\mathrm{MMSE}}$ is lower than $\mathrm{BWE}_{\mathrm{ES}}$. When $\phi$ is larger than $\phi_{2}, \mathrm{BWE}_{\mathrm{MMSE}}$ is the largest compared to the other two methods. In general, while $\phi$ is lower than $\phi_{1}$, the MMSE method is the best for reducing the bullwhip effect, and while $\phi$ is higher than $\phi_{1}$, the MA method is the best.

However, comparing the two figures, we find that as the span $k$ increases, the bullwhip effects for the three forecasting methods overall decrease, and the values of $\phi_{1}$ and $\phi_{2}$ are lessened. This phenomenon reveals that when we choose a larger span $k$, the extent of $\phi$ is larger for the MA which is the best method to predict the bullwhip effect.

In Figure 13, we set $\phi=0.5, \theta=0.3, L_{1}=1, L_{2}=2, \lambda_{1}=$ $\lambda_{2}=0.4$, and $k=4$ and then study the bullwhip effect for the three forecasting methods under the condition of various market shares $\alpha$. We observe that the bullwhip effect is the smallest by the MMSE forecasting method whatever $\alpha$ is. And the bullwhip effect under the ES method is the worst whatever $\alpha$ is. This conclusion is related to the value of $\phi$ when we select a certain $k$.

Figure 14 shows the curved surface of the bullwhip effect by varying $\phi$ and $\theta$ for the three forecasting methods. It is observed that $\mathrm{BWE}_{\mathrm{ES}}$ is always larger than $\mathrm{BWE}_{\mathrm{MA}}$ whatever $\theta$ is as long as $\lambda_{1}=\lambda_{2}=2 /(k+1)$ for the fixed value of $\phi$. When $\theta$ increases from -1 to $1, \mathrm{BWE}_{\mathrm{MA}}$ is the smallest while $\theta$ is less than a certain value, and $B W E_{M M S E}$ is the best while $\theta$ is more than that certain value. In addition, there is also a phenomenon where $\mathrm{BWE}_{\mathrm{MMSE}}$ is all along the largest for any value of $\phi$ when $\theta$ approaches negative one. 


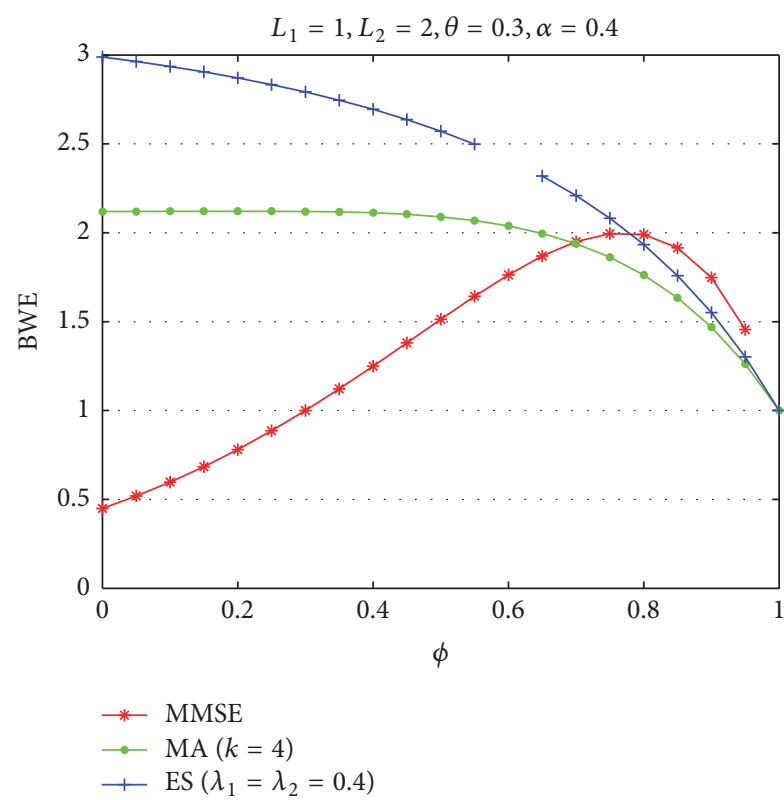

(a)

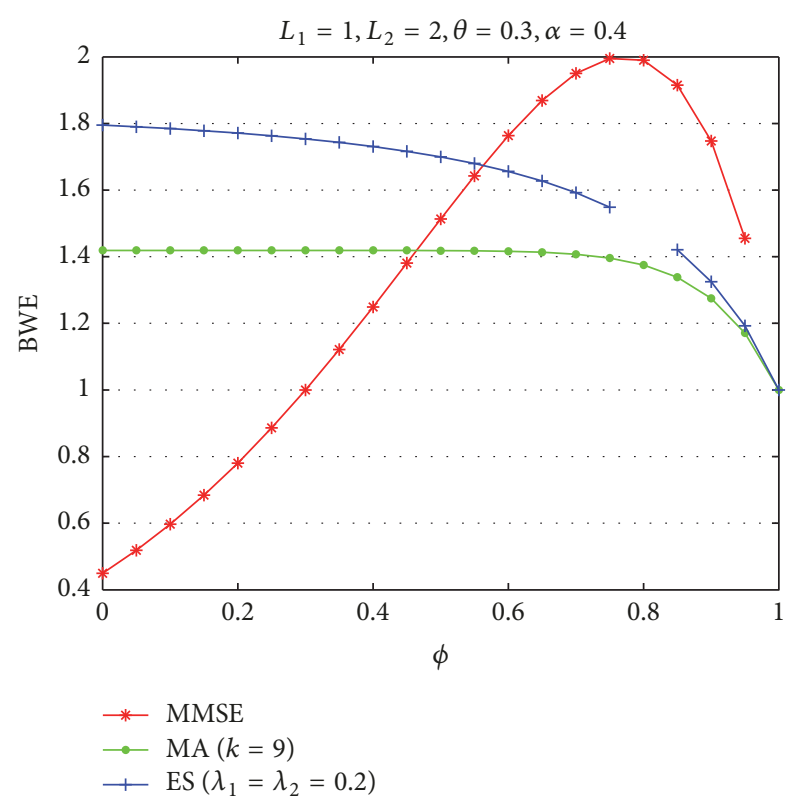

(b)

FIGURE 12: Comparison of the three forecasting methods by varying $\phi$ in the case of $k=4$ or $k=9$.

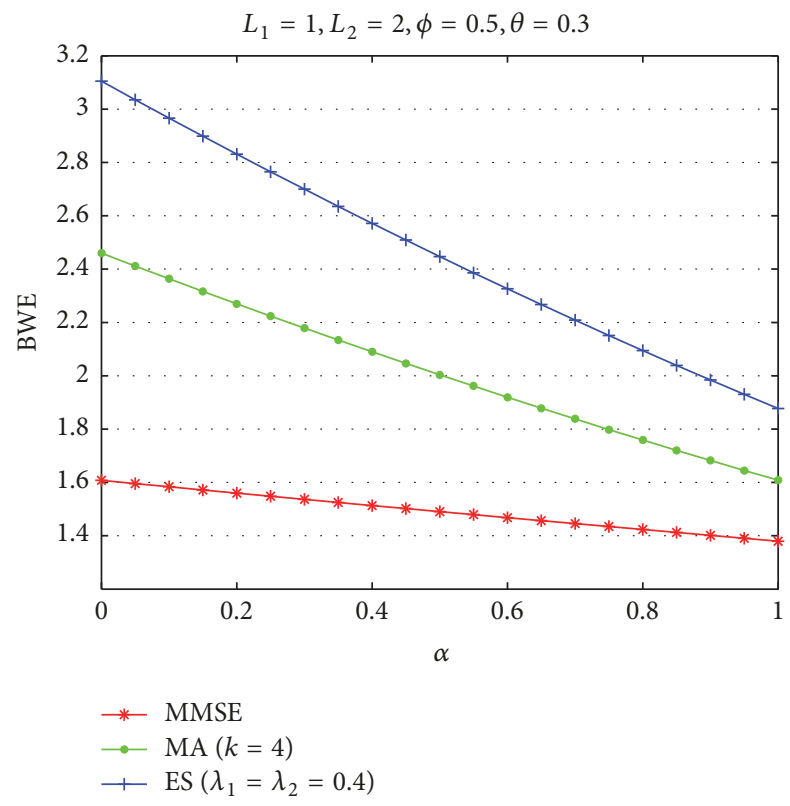

FIGURE 13: Comparison of the three forecasting methods by varying $\alpha$ in the case of $k=4$.

In summary, in order to reduce the bullwhip effect, we will select a reasonable forecasting method according to the values of various parameters.

\section{Conclusions}

In this paper, we mainly study the impact of three forecasting methods on the bullwhip effect measure considering the market share in a stable mature supply chain with two retailers.

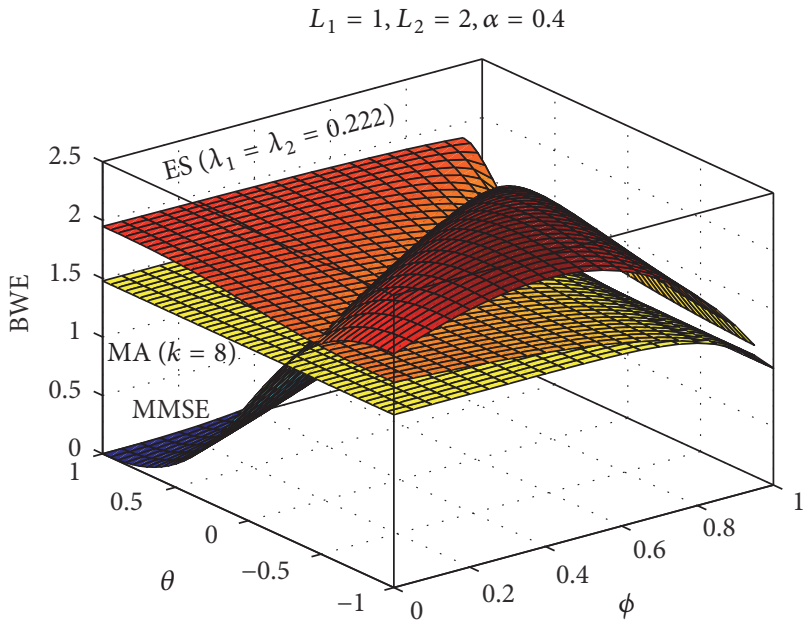

FIGURE 14: Comparison of the three forecasting methods by varying $\phi$ and $\theta$ in the case of $k=8$.

We first quantify the bullwhip effect in a two-level supply chain with two retailers considering the market share. In the $\operatorname{ARMA}(1,1)$ demand model, we use the three forecasting methods to establish the expressions of the bullwhip effect. By simulations, some results are obtained. (1) The larger the market share of the retailer with long lead time is, the greater the bullwhip effect is, no matter what the forecasting method is. (2) The bullwhip effect is increased along with the increasing of $\theta$ for the MA and ES method and, however, it is dampened for the MMSE method. (3) The bullwhip effect has a positive correlation with the lead time and the smoothing factors $\lambda$ and has a negative correlation with the span $k$. (4) By comparison, the MA is always better than the ES for reducing the bullwhip effect in our supply chain model. When $\phi$ is 
lower than a certain value, the MMSE method is the best for reducing the bullwhip effect; otherwise, the MA method is the best.

Our findings give some useful insights for supply chain managers in the consumer electronics industry. Firstly, the retailers should make it clear what kind of pattern the demand process follows and choose a suitable forecasting method to dampen the bullwhip effect. Secondly, the manufacturer should pay more attention to the retailer who occupies a large market share on purpose and reduce its lead time to dampen the bullwhip effect.

From the view of entropy, we see that the autocorrelation coefficient can impact the uncertainty of the order. The minimum of the entropy is around $\phi=0.672$, and the maximum of the entropy is around $\phi=1$.

The research presented in this paper proposes several future directions for improvement of our understanding of market share. First, we can further study the effect of unfixed market share on the bullwhip effect in an unstable supply chain. Second, we only consider the order-up-to inventory policy and three traditional demand forecasting methods. Therefore, other new forecast methods and complex inventory policies can be studied in future research. Furthermore, price is the key factor on the bullwhip effect. So, introducing the retailer's price into the demand model to analyze the complexity and stability of the supply chain system is another future direction.

\section{Appendix}

\section{A. A Proof of Proposition 1}

$$
\begin{aligned}
\operatorname{Var}\left(\varepsilon_{t-1}\right) & =\operatorname{Var}\left(\varepsilon_{t-2}\right)=\operatorname{Var}\left(\varepsilon_{t}\right) \\
& =\frac{1-\phi^{2}}{1+\theta^{2}-2 \phi \theta} \operatorname{Var}\left(d_{t}\right) .
\end{aligned}
$$

According to Feng and $\mathrm{Ma}$ [17], there is

$$
\operatorname{Cov}\left(d_{t-1}, d_{t-k-1}\right)=\phi^{k-1} \frac{(\phi-\theta)(1-\phi \theta)}{1+\theta^{2}-2 \phi \theta} \operatorname{Var}\left(d_{t}\right) .
$$

According to Duc et al. [16], we have

$$
\begin{aligned}
& \operatorname{Cov}\left(d_{t-1}, \varepsilon_{t-1}\right)=\operatorname{Var}\left(\varepsilon_{t-1}\right), \\
& \operatorname{Cov}\left(d_{t-1}, \varepsilon_{t-2}\right)=(\phi-\theta) \operatorname{Var}\left(\varepsilon_{t-1}\right) .
\end{aligned}
$$

Take the variance of (27); we get

$$
\begin{aligned}
& \operatorname{Var}\left(q_{t}\right)=\operatorname{Var}\left(\left(1+\alpha \phi A_{1}+(1-\alpha) \phi A_{2}\right) d_{t-1}\right. \\
& \quad-\left(\alpha \phi A_{1}+(1-\alpha) \phi A_{2}\right) d_{t-2} \\
& \quad-\left(\alpha \theta A_{1}+(1-\alpha) \theta A_{2}\right) \varepsilon_{t-1} \\
& \left.\quad+\left(\alpha \theta A_{1}+(1-\alpha) \theta A_{2}\right) \varepsilon_{t-2}\right) \\
& \quad=\operatorname{Var}\left(\left(1+\alpha \phi A_{1}+(1-\alpha) \phi A_{2}\right) d_{t-1}\right)
\end{aligned}
$$

$$
\begin{aligned}
& +\operatorname{Var}\left((1-\alpha)\left(\phi A_{2}+1\right) d_{t-2}\right) \\
& +\operatorname{Var}\left(\left(\alpha \theta A_{1}+(1-\alpha) \theta A_{2}\right) \varepsilon_{t-1}\right) \\
& +\operatorname{Var}\left(\left(\alpha \theta A_{1}+(1-\alpha) \theta A_{2}\right) \varepsilon_{t-2}\right)-2\left(1+\alpha \phi A_{1}\right. \\
& \left.+(1-\alpha) \phi A_{2}\right)\left(\alpha \phi A_{1}+(1-\alpha) \phi A_{2}\right) \\
& \cdot \operatorname{Cov}\left(d_{t-1}, d_{t-2}\right)-2\left(1+\alpha \phi A_{1}+(1-\alpha) \phi A_{2}\right) \\
& \cdot\left(\alpha \theta A_{1}+(1-\alpha) \theta A_{2}\right) \operatorname{Cov}\left(d_{t-1}, \varepsilon_{t-1}\right)+2(1 \\
& \left.+\alpha \phi A_{1}+(1-\alpha) \phi A_{2}\right)\left(\alpha \theta A_{1}+(1-\alpha) \theta A_{2}\right) \\
& \cdot \operatorname{Cov}\left(d_{t-1}, \varepsilon_{t-2}\right)+2\left(\alpha \phi A_{1}+(1-\alpha) \phi A_{2}\right) \\
& \cdot\left(\alpha \theta A_{1}+(1-\alpha) \theta A_{2}\right) \operatorname{Cov}\left(d_{t-2}, \varepsilon_{t-1}\right) \\
& -2\left(\alpha \phi A_{1}+(1-\alpha) \phi A_{2}\right)\left(\alpha \theta A_{1}+(1-\alpha) \theta A_{2}\right) \\
& \cdot \operatorname{Cov}\left(d_{t-2}, \varepsilon_{t-2}\right)-2\left(\alpha \theta A_{1}+(1-\alpha) \theta A_{2}\right)^{2} \\
& \cdot \operatorname{Cov}\left(\varepsilon_{t-1}, \varepsilon_{t-2}\right) \cdot
\end{aligned}
$$

Bring (A.1)-(A.3) into (A.4) and simplify the original equation; we can get the variance of the order quantity under the MMSE forecasting method as follows:

$$
\begin{aligned}
& \operatorname{Var}\left(q_{t}\right)=\left(\left(1+\alpha \phi A_{1}+(1-\alpha) \phi A_{2}\right)^{2}+\left(\alpha \phi A_{1}\right.\right. \\
& \left.\left.+(1-\alpha) \phi A_{2}\right)^{2}\right) \operatorname{Var}\left(d_{t}\right)+2\left(\alpha \theta A_{1}+(1-\alpha)\right. \\
& \left.\cdot \theta A_{2}\right)^{2} \operatorname{Var}\left(\varepsilon_{t}\right)-2\left(1+\alpha \phi A_{1}+(1-\alpha) \phi A_{2}\right) \\
& \cdot\left(\alpha \phi A_{1}+(1-\alpha) \phi A_{2}\right) \frac{(\phi-\theta)(1-\phi \theta)}{1+\theta^{2}-2 \phi \theta} \operatorname{Var}\left(d_{t}\right) \\
& -2\left(1+\alpha \phi A_{1}+(1-\alpha) \phi A_{2}\right)\left(\alpha \theta A_{1}+(1-\alpha)\right. \\
& \left.\cdot \theta A_{2}\right) \operatorname{Var}\left(\varepsilon_{t-1}\right)+2\left(1+\alpha \phi A_{1}+(1-\alpha) \phi A_{2}\right) \\
& \cdot\left(\alpha \theta A_{1}+(1-\alpha) \theta A_{2}\right)(\phi-\theta) \operatorname{Var}\left(\varepsilon_{t-1}\right) \\
& -2\left(\alpha \phi A_{1}+(1-\alpha) \phi A_{2}\right)\left(\alpha \theta A_{1}+(1-\alpha) \theta A_{2}\right) \\
& \cdot \operatorname{Var}\left(\varepsilon_{t-2}\right)=\left[\left(1+\alpha \phi A_{1}+(1-\alpha) \phi A_{2}\right)^{2}\right. \\
& +\left(\alpha \phi A_{1}+(1-\alpha) \phi A_{2}\right)^{2}-2\left(1+\alpha \phi A_{1}\right. \\
& \left.+(1-\alpha) \phi A_{2}\right)\left(\alpha \phi A_{1}+(1-\alpha) \phi A_{2}\right) \\
& . \\
& (\phi-\theta)(1-\phi \theta) \\
& 1+\theta^{2}-2 \phi \theta \\
& \cdot \frac{1-\phi^{2}}{1+\theta^{2}-2 \phi \theta}\left(\left(\alpha \theta A_{1}+(1-\alpha) \theta A_{2}\right)^{2}\right. \\
& -\left(1+\alpha \phi A_{1}+(1-\alpha) \phi A_{2}\right) \\
& \cdot\left(\alpha \theta A_{1}+(1-\alpha) \theta A_{2}\right)
\end{aligned}
$$




$$
\begin{aligned}
& +\left(1+\alpha \phi A_{1}+(1-\alpha) \phi A_{2}\right) \\
& \cdot\left(\alpha \theta A_{1}+(1-\alpha) \theta A_{2}\right)(\phi-\theta) \\
& \left.\left.-\left(\alpha \phi A_{1}+(1-\alpha) \phi A_{2}\right)\left(\alpha \theta A_{1}+(1-\alpha) \theta A_{2}\right)\right)\right] \\
& \cdot \operatorname{Var}\left(d_{t}\right)
\end{aligned}
$$

This completes the proof of Proposition 1.

\section{B. A Proof of Proposition 2}

The variance of the total order quantity under the MA forecasting method can be derived from (33) as follows:

$$
\begin{aligned}
& \operatorname{Var}\left(q_{t}\right)=\operatorname{Var}\left(\left(1+\alpha \frac{L_{1}}{k}+(1-\alpha) \frac{L_{2}}{k}\right) d_{t-1}\right. \\
& \left.-\left(\alpha \frac{L_{1}}{k}+(1-\alpha) \frac{L_{2}}{k}\right) d_{t-k-1}\right)=\left(1+\alpha \frac{L_{1}}{k}\right. \\
& \left.+(1-\alpha) \frac{L_{2}}{k}\right)^{2} \operatorname{Var}\left(d_{t-1}\right)+\left(\alpha \frac{L_{1}}{k}+(1-\alpha) \frac{L_{2}}{k}\right)^{2} \\
& +\operatorname{Var}\left(d_{t-k-1}\right)-2\left(1+\alpha \frac{L_{1}}{k}+(1-\alpha) \frac{L_{2}}{k}\right)\left(\alpha \frac{L_{1}}{k}\right. \\
& \left.+(1-\alpha) \frac{L_{2}}{k}\right) \operatorname{Cov}\left(d_{t-1}, d_{t-k-1}\right) .
\end{aligned}
$$

According to (A.2), the variance can be simplified as

$$
\begin{aligned}
& \operatorname{Var}\left(q_{t}\right)=\left[\left(1+\alpha \frac{L_{1}}{k}+(1-\alpha) \frac{L_{2}}{k}\right)^{2}\right. \\
& +\left(\alpha \frac{L_{1}}{k}+(1-\alpha) \frac{L_{2}}{k}\right)^{2} \\
& -2\left(1+\alpha \frac{L_{1}}{k}+(1-\alpha) \frac{L_{2}}{k}\right)\left(\alpha \frac{L_{1}}{k}+(1-\alpha) \frac{L_{2}}{k}\right) \\
& \left.\cdot \phi^{k-1} \frac{(\phi-\theta)(1-\phi \theta)}{1+\theta^{2}-2 \phi \theta}\right] \operatorname{Var}\left(d_{t}\right) .
\end{aligned}
$$

This completes the proof of Proposition 2.

\section{A Proof of Proposition 3}

The variance of the total order quantity under the ES forecasting method can be derived from (42) as follows:

$$
\begin{aligned}
& \operatorname{Var}\left(q_{t}\right)=\operatorname{Var}\left(\left(1+\alpha \lambda_{1} L_{1}+(1-\alpha) \lambda_{2} L_{2}\right) d_{t-1}\right. \\
& \left.\quad-\lambda_{1} L_{1} \widehat{d}_{1, t-1}-\lambda_{2} L_{2} \widehat{d}_{2, t-1}\right)=\left(1+\alpha \lambda_{1} L_{1}\right. \\
& \left.\quad+(1-\alpha) \lambda_{2} L_{2}\right)^{2} \operatorname{Var}\left(d_{t-1}\right)+\left(\lambda_{1} L_{1}\right)^{2} \operatorname{Var}\left(\widehat{d}_{1, t-1}\right)
\end{aligned}
$$

$$
\begin{aligned}
& +\left(\lambda_{2} L_{2}\right)^{2} \operatorname{Var}\left(\widehat{d}_{2, t-1}\right)-2\left(1+\alpha \lambda_{1} L_{1}\right. \\
& \left.+(1-\alpha) \lambda_{2} L_{2}\right) \lambda_{1} L_{1} \operatorname{Cov}\left(d_{t-1}, \widehat{d}_{1, t-1}\right)-2(1 \\
& \left.+\alpha \lambda_{1} L_{1}+(1-\alpha) \lambda_{2} L_{2}\right) \lambda_{2} L_{2} \operatorname{Cov}\left(d_{t-1}, \widehat{d}_{2, t-1}\right) \\
& +2 \lambda_{1} L_{1} \lambda_{2} L_{2} \operatorname{Cov}\left(\widehat{d}_{1, t-1}, \widehat{d}_{2, t-1}\right)
\end{aligned}
$$

where

$$
\begin{aligned}
& \operatorname{Var}\left(\widehat{d}_{1, t-1}\right)=\operatorname{Var}\left(\sum_{i=0}^{\infty} \lambda_{1}\left(1-\lambda_{1}\right)^{i} d_{1, t-i-2}\right) \\
& =\lambda_{1}^{2} \sum_{i=0}^{\infty}\left(1-\lambda_{1}\right)^{2 i} \operatorname{Var}\left(d_{1, t-i-2}\right) \\
& +2 \lambda_{1}^{2} \sum_{i=0}^{\infty} \sum_{j>i}^{\infty}\left(1-\lambda_{1}\right)^{i}\left(1-\lambda_{1}\right)^{j} \\
& \cdot \operatorname{Cov}\left(d_{1, t-i-2}, d_{1, t-j-2}\right)=\lambda_{1}^{2} \sum_{i=0}^{\infty}\left(1-\lambda_{1}\right)^{2 i} \\
& \cdot \alpha^{2} \operatorname{Var}\left(d_{t-i-2}\right)+2 \lambda_{1}^{2} \alpha^{2} \sum_{i=0}^{\infty} \sum_{j>i}^{\infty}\left(1-\lambda_{1}\right)^{i+j} \\
& \cdot \operatorname{Cov}\left(d_{t-i-2}, d_{t-j-2}\right)=\alpha^{2} \lambda_{1}^{2} \frac{1}{\lambda_{1}\left(2-\lambda_{1}\right)} \operatorname{Var}\left(d_{t}\right) \\
& +2 \lambda_{1}^{2} \alpha^{2} \sum_{i=0}^{\infty} \sum_{j>i}^{\infty}\left(1-\lambda_{1}\right)^{i+j} \phi^{j-i-1}
\end{aligned}
$$

$$
\begin{aligned}
& \cdot \frac{(\phi-\theta)(1-\phi \theta)}{1+\theta^{2}-2 \phi \theta} \operatorname{Var}\left(d_{t}\right)=\alpha^{2} \lambda_{1}^{2} \operatorname{Var}\left(d_{t}\right) \\
& \cdot\left[\frac{1}{\lambda_{1}\left(2-\lambda_{1}\right)}+2 \frac{(\phi-\theta)(1-\phi \theta)}{\left(1+\theta^{2}-2 \phi \theta\right)}\right. \\
& \left.\cdot \frac{\left(1-\lambda_{1}\right)}{\lambda_{1}\left(2-\lambda_{1}\right)\left(1-\left(1-\lambda_{1}\right) \phi\right)}\right]=\frac{\lambda_{1} \alpha^{2}}{2-\lambda_{1}}[1 \\
& \left.+\frac{2\left(1-\lambda_{1}\right)}{1-\left(1-\lambda_{1}\right) \phi} \frac{(\phi-\theta)(1-\phi \theta)}{\left(1+\theta^{2}-2 \phi \theta\right)}\right] \operatorname{Var}\left(d_{t}\right),
\end{aligned}
$$

and, similarly, we have

$$
\begin{aligned}
& \operatorname{Var}\left(\widehat{d}_{2, t-1}\right)=\operatorname{Var}\left(\sum_{i=0}^{\infty} \lambda_{2}\left(1-\lambda_{2}\right)^{i} d_{2, t-i-2}\right) \\
& \quad=\lambda_{2}^{2} \sum_{i=0}^{\infty}\left(1-\lambda_{2}\right)^{2 i}(1-\alpha)^{2} \operatorname{Var}\left(d_{t-i-2}\right)+2 \lambda_{2}^{2}(1 \\
& -\alpha)^{2} \sum_{i=0}^{\infty} \sum_{j>i}^{\infty}\left(1-\lambda_{2}\right)^{i+j} \operatorname{Cov}\left(d_{t-i-2}, d_{t-j-2}\right)=(1 \\
& -\alpha)^{2} \lambda_{2}^{2} \operatorname{Var}\left(d_{t}\right)\left[\frac{1}{\lambda_{2}\left(2-\lambda_{2}\right)}+2\right.
\end{aligned}
$$




$$
\begin{aligned}
& \left.\cdot \frac{(\phi-\theta)(1-\phi \theta)}{\left(1+\theta^{2}-2 \phi \theta\right)} \frac{\left(1-\lambda_{2}\right)}{\lambda_{2}\left(2-\lambda_{2}\right)\left(1-\left(1-\lambda_{2}\right) \phi\right)}\right] \\
& =\frac{\lambda_{2}(1-\alpha)^{2}}{2-\lambda_{2}}\left[1+\frac{2\left(1-\lambda_{2}\right)}{1-\left(1-\lambda_{2}\right) \phi}\right. \\
& \left.\cdot \frac{(\phi-\theta)(1-\phi \theta)}{\left(1+\theta^{2}-2 \phi \theta\right)}\right] \operatorname{Var}\left(d_{t}\right) \text {, } \\
& \operatorname{Cov}\left(d_{t-1}, \widehat{d}_{1, t-1}\right)=\operatorname{Cov}\left(d_{t-1}\right. \text {, } \\
& \left.\sum_{i=0}^{\infty} \lambda_{1}\left(1-\lambda_{1}\right)^{i} d_{1, t-i-2}\right)=\alpha \lambda_{1} \sum_{i=0}^{\infty}\left(1-\lambda_{1}\right)^{i} \\
& \cdot \operatorname{Cov}\left(d_{t-1}, d_{t-i-2}\right)=\alpha \lambda_{1} \sum_{i=0}^{\infty}\left(1-\lambda_{1}\right)^{i} \phi^{i} \\
& \cdot \frac{(\phi-\theta)(1-\phi \theta)}{1+\theta^{2}-2 \phi \theta} \operatorname{Var}\left(d_{t}\right)=\frac{\alpha \lambda_{1}}{1-\left(1-\lambda_{1}\right) \phi} \\
& \cdot \frac{(\phi-\theta)(1-\phi \theta)}{1+\theta^{2}-2 \phi \theta} \operatorname{Var}\left(d_{t}\right), \\
& \operatorname{Cov}\left(d_{t-1}, \widehat{d}_{2, t-1}\right)=\operatorname{Cov}\left(d_{t-1}\right. \text {, } \\
& \left.\sum_{i=0}^{\infty} \lambda_{2}\left(1-\lambda_{2}\right)^{i} d_{2, t-i-2}\right)=(1-\alpha) \lambda_{2} \sum_{i=0}^{\infty}(1 \\
& \left.-\lambda_{2}\right)^{i} \operatorname{Cov}\left(d_{t-1}, d_{t-i-2}\right)=\frac{(1-\alpha) \lambda_{2}}{1-\left(1-\lambda_{2}\right) \phi} \\
& \cdot \frac{(\phi-\theta)(1-\phi \theta)}{1+\theta^{2}-2 \phi \theta} \operatorname{Var}\left(d_{t}\right) \text {, }
\end{aligned}
$$

$$
\begin{aligned}
& \operatorname{Cov}\left(\widehat{d}_{1, t-1}, \widehat{d}_{2, t-1}\right)=\operatorname{Cov}\left(\sum_{i=0}^{\infty} \lambda_{1}\left(1-\lambda_{1}\right)^{i} d_{1, t-i-2},\right. \\
& \left.\sum_{j=0}^{\infty} \lambda_{2}\left(1-\lambda_{2}\right)^{j} d_{2, t-j-2}\right)=\lambda_{1} \lambda_{2} \alpha(1-\alpha) \\
& \cdot \sum_{i=0}^{\infty}\left(1-\lambda_{1}\right)^{i} \operatorname{Cov}\left(d_{t-i-2}, \sum_{j=0}^{\infty}\left(1-\lambda_{2}\right)^{j} d_{2, t-j-2}\right) \\
& =\lambda_{1} \lambda_{2} \alpha(1-\alpha) \sum_{i=0}^{\infty}\left(1-\lambda_{1}\right)^{i} \\
& \cdot \sum_{j=0}^{\infty}\left(1-\lambda_{2}\right)^{j} \operatorname{Cov}\left(d_{t-i-2}, d_{t-j-2}\right)=\lambda_{1} \lambda_{2} \alpha(1 \\
& -\alpha) \operatorname{Var}\left(d_{t}\right) \sum_{i=0}^{\infty}\left(1-\lambda_{1}\right)^{i} \\
& \cdot\left(\sum_{j=0}^{i-1}\left(1-\lambda_{2}\right)^{j} \phi^{i-j-1} \frac{(\phi-\theta)(1-\phi \theta)}{1+\theta^{2}-2 \phi \theta}\right. \\
& +\sum_{j>i}^{\infty}\left(1-\lambda_{2}\right)^{j} \phi^{j-i-1} \frac{(\phi-\theta)(1-\phi \theta)}{1+\theta^{2}-2 \phi \theta} \\
& \left.+\left(1-\lambda_{2}\right)^{i}\right) \cdot
\end{aligned}
$$

Substituting (C.2)-(C.3) into (C.1) and simplifying the equation, we can derive the expression of the variance of the order quantity of two retailers under the ES forecasting method as follows:

$$
\begin{aligned}
& \operatorname{Var}\left(q_{t}\right)=\left(1+\alpha \lambda_{1} L_{1}+(1-\alpha) \lambda_{2} L_{2}\right)^{2} \operatorname{Var}\left(d_{t}\right)+\frac{L_{1}^{2} \lambda_{1}^{3} \alpha^{2}}{2-\lambda_{1}}\left[1+\frac{2\left(1-\lambda_{1}\right)}{1-\left(1-\lambda_{1}\right) \phi} \frac{(\phi-\theta)(1-\phi \theta)}{\left(1+\theta^{2}-2 \phi \theta\right)}\right] \operatorname{Var}\left(d_{t}\right) \\
& \quad+\frac{L_{2}^{2} \lambda_{2}^{3}(1-\alpha)^{2}}{2-\lambda_{2}}\left[1+\frac{2\left(1-\lambda_{2}\right)}{1-\left(1-\lambda_{2}\right) \phi} \frac{(\phi-\theta)(1-\phi \theta)}{\left(1+\theta^{2}-2 \phi \theta\right)}\right] \operatorname{Var}\left(d_{t}\right)-2\left(1+\alpha \lambda_{1} L_{1}+(1-\alpha) \lambda_{2} L_{2}\right) \frac{\alpha L_{1} \lambda_{1}^{2}}{1-\left(1-\lambda_{1}\right) \phi} \\
& \quad . \frac{(\phi-\theta)(1-\phi \theta)}{1+\theta^{2}-2 \phi \theta} \operatorname{Var}\left(d_{t}\right)-2\left(1+\alpha \lambda_{1} L_{1}+(1-\alpha) \lambda_{2} L_{2}\right) \frac{(1-\alpha) L_{2} \lambda_{2}^{2}}{1-\left(1-\lambda_{2}\right) \phi} \frac{(\phi-\theta)(1-\phi \theta)}{1+\theta^{2}-2 \phi \theta} \operatorname{Var}\left(d_{t}\right) \\
& +2 \lambda_{1}^{2} \lambda_{2}^{2} L_{1} L_{2} \alpha(1-\alpha) \operatorname{Var}\left(d_{t}\right) \sum_{i=0}^{\infty}\left(1-\lambda_{1}\right)^{i} \\
& \quad \cdot\left(\sum_{j=0}^{i-1}\left(1-\lambda_{2}\right)^{j} \phi^{i-j-1} \frac{(\phi-\theta)(1-\phi \theta)}{1+\theta^{2}-2 \phi \theta}+\sum_{j>i}^{\infty}\left(1-\lambda_{2}\right)^{j} \phi^{j-i-1} \frac{(\phi-\theta)(1-\phi \theta)}{1+\theta^{2}-2 \phi \theta}+\left(1-\lambda_{2}\right)^{i}\right)=\operatorname{Var}\left(d_{t}\right)\left[\left(1+\alpha \lambda_{1} L_{1}\right.\right. \\
& \left.+(1-\alpha) \lambda_{2} L_{2}\right)^{2}+\frac{L_{1}^{2} \lambda_{1}^{3} \alpha^{2}}{2-\lambda_{1}}\left(1+\frac{2\left(1-\lambda_{1}\right)}{1-\left(1-\lambda_{1}\right) \phi} \frac{(\phi-\theta)(1-\phi \theta)}{\left(1+\theta^{2}-2 \phi \theta\right)}\right)+\frac{L_{2}^{2} \lambda_{2}^{3}(1-\alpha)^{2}}{2-\lambda_{2}}(1
\end{aligned}
$$




$$
\begin{aligned}
& \left.+\frac{2\left(1-\lambda_{2}\right)}{1-\left(1-\lambda_{2}\right) \phi} \frac{(\phi-\theta)(1-\phi \theta)}{\left(1+\theta^{2}-2 \phi \theta\right)}\right)-2\left(1+\alpha \lambda_{1} L_{1}+(1-\alpha) \lambda_{2} L_{2}\right) \frac{(\phi-\theta)(1-\phi \theta)}{1+\theta^{2}-2 \phi \theta}\left(\frac{\alpha L_{1} \lambda_{1}^{2}}{1-\left(1-\lambda_{1}\right) \phi}\right. \\
& \left.+\frac{(1-\alpha) L_{2} \lambda_{2}^{2}}{1-\left(1-\lambda_{2}\right) \phi}\right)+2 \lambda_{1}^{2} \lambda_{2}^{2} L_{1} L_{2} \alpha(1-\alpha) \\
& \left.\cdot \sum_{i=0}^{\infty}\left(1-\lambda_{1}\right)^{i}\left(\sum_{j=0}^{i-1}\left(1-\lambda_{2}\right)^{j} \phi^{i-j-1} \frac{(\phi-\theta)(1-\phi \theta)}{1+\theta^{2}-2 \phi \theta}+\sum_{j>i}^{\infty}\left(1-\lambda_{2}\right)^{j} \phi^{j-i-1} \frac{(\phi-\theta)(1-\phi \theta)}{1+\theta^{2}-2 \phi \theta}+\left(1-\lambda_{2}\right)^{i}\right)\right] \\
& =\operatorname{Var}\left(d_{t}\right)\left[\left(1+\alpha \lambda_{1} L_{1}+(1-\alpha) \lambda_{2} L_{2}\right)^{2}+\frac{L_{1}^{2} \lambda_{1}^{3} \alpha^{2}}{2-\lambda_{1}}\left(1+\frac{2\left(1-\lambda_{1}\right)}{1-\left(1-\lambda_{1}\right) \phi} \frac{(\phi-\theta)(1-\phi \theta)}{\left(1+\theta^{2}-2 \phi \theta\right)}\right)+\frac{L_{2}^{2} \lambda_{2}^{3}(1-\alpha)^{2}}{2-\lambda_{2}}(1\right. \\
& \left.+\frac{2\left(1-\lambda_{2}\right)}{1-\left(1-\lambda_{2}\right) \phi} \frac{(\phi-\theta)(1-\phi \theta)}{\left(1+\theta^{2}-2 \phi \theta\right)}\right)-2\left(1+\alpha \lambda_{1} L_{1}+(1-\alpha) \lambda_{2} L_{2}\right) \frac{(\phi-\theta)(1-\phi \theta)}{1+\theta^{2}-2 \phi \theta}\left(\frac{\alpha L_{1} \lambda_{1}^{2}}{1-\left(1-\lambda_{1}\right) \phi}\right. \\
& \left.+\frac{(1-\alpha) L_{2} \lambda_{2}^{2}}{1-\left(1-\lambda_{2}\right) \phi}\right)+2 \lambda_{1}^{2} \lambda_{2}^{2} L_{1} L_{2} \alpha(1-\alpha)\left(\frac{(\phi-\theta)(1-\phi \theta)}{1+\theta^{2}-2 \phi \theta} \frac{1}{\left(\phi+\lambda_{2}-1\right)\left(1-\left(1-\lambda_{1}\right) \phi\right)}\right. \\
& \left.+\frac{1}{1-\left(1-\lambda_{1}\right)\left(1-\lambda_{2}\right)}\left(1+\frac{(\phi-\theta)(1-\phi \theta)}{1+\theta^{2}-2 \phi \theta}\left(\frac{1-\lambda_{2}}{1-\left(1-\lambda_{2}\right) \phi}-\frac{1}{\phi+\lambda_{2}-1}\right)\right)\right]
\end{aligned}
$$

This completes the proof of Proposition 3.

\section{Conflicts of Interest}

The authors declare no conflicts of interest.

\section{Acknowledgments}

This research was supported by the National Natural Science Foundation of China (71571131). The authors would like to appreciate Dr. Weiya Di and Dr. Xiaogang Ma's valuable advice and help. All authors have read and approved the final manuscript.

\section{References}

[1] H. L. Lee, P. Padmanabhan, and S. Whang, "Information distortion in a supply chain: the bullwhip effect," Management Science, vol. 43, no. 4, pp. 546-558, 1997.

[2] H. L. Lee, P. Padmanabhan, and S. Whang, "Bullwhip Effect in a Supply Chain," Sloan Management Review, vol. 38, no. 2, pp. 93-102, 1997.

[3] J. W. Forrester, "Industrial Dynamics-A Major Breakthrough for Decision Making," Harvard Business Review, vol. 36, no. 4, pp. 37-66, 1958.

[4] J. W. Forrester, Industrial Dynamics, MIT Press, Cambridge, Mass, USA, 1961

[5] J. Sterman, "Optimal Policy for A Multi-product, Dynamic, Nonstationary Inventory Problem," Management Science, vol. 18, no. 12, pp. 206-222, 1989.

[6] F. Chen, Z. Drezner, J. K. Ryan, and D. Simchi-Levi, "Quantifying the bullwhip effect in a simple supply chain: the impact of forecasting, lead times, and information," Management Science, vol. 46, no. 3, pp. 436-443, 2000.

[7] F. Chen, J. K. Ryan, and D. Simchi-Levi, "The impact of exponential smoothing forecasts on the bullwhip effect," Naval Research Logistics, vol. 47, no. 4, pp. 269-286, 2000.

[8] X. Zhang, "The impact of forecasting methods on the bullwhip effect," International Journal of Production Economics, vol. 88, no. 1, pp. 15-27, 2004.

[9] H. L. Lee, K. C. So, and C. S. Tang, "Value of information sharing in a two-level supply chain," Management Science, vol. 46, no. 5, pp. 626-643, 2000.

[10] H. T. Luong, "Measure of bullwhip effect in supply chains with autoregressive demand process," European Journal of Operational Research, vol. 180, no. 3, pp. 1086-1097, 2007.

[11] H. T. Luong and N. H. Phien, "Measure of bullwhip effect in supply chains: The case of high order autoregressive demand process," European Journal of Operational Research, vol. 183, no. 1, pp. 197-209, 2007.

[12] T. T. H. Duc, H. T. Luong, and Y. D. Kim, "Effect of the thirdparty warehouse on bullwhip effect and inventory cost in supply chains," International Journal of Production Economics, vol. 124, no. 2, pp. 395-407, 2010.

[13] S. C. Graves, "A single-item inventory model for a nonstationary demand process," Manufacturing \& Service Operations Management, vol. 1, no. 1, pp. 50-61, 1999.

[14] R. S. Pindyck and D. L. Rubinfeld, Econometric Models and Economic Forecasts, Irwin McGraw-Hill, Boston, MA, USA, 4th edition, 1998.

[15] S. M. Disney, I. Farasyn, M. Lambrecht, D. Towill, and W. Van de Velde, "Taming the bullwhip effect whilst watching customer service in a single supply chain echelon," European Journal of Operational Research, vol. 173, no. 1, pp. 151-172, 2006.

[16] T. T. Duc, H. T. Luong, and Y.-D. Kim, "A measure of bullwhip effect in supply chains with a mixed autoregressive-moving 
average demand process," European Journal of Operational Research, vol. 187, no. 1, pp. 243-256, 2008.

[17] Y. Feng and J. H. Ma, "Demand and Forecasting in Supply Chains Based on $\operatorname{ARMA}(1,1)$ Demand process," Industrial Engineering Journal, vol. 11, no. 5, pp. 50-55, 2008.

[18] J. H. Ma and X. G. Ma, "A comparison of bullwhip effect under various forecasting techniques in supply chains with two retailers," Abstract and Applied Analysis, vol. 2013, Article ID 796384, 14 pages, 2013.

[19] J. H. Ma and J. Zhang, "Measure of bullwhip effect considering stochastic disturbance based on price fluctuations in a supply chain with two retailers," Wseas Transactions on Mathematics, vol. 14, pp. 127-149, 2015.

[20] S. Bandyopadhyay and R. Bhattacharya, "A generalized measure of bullwhip effect in supply chain with ARMA demand process under various replenishment policies," International Journal of Advanced Manufacturing Technology, vol. 68, no. 5-8, pp. 963979, 2013.

[21] K. Gilbert, "An ARIMA supply chain model," Management Science, vol. 51, no. 2, pp. 305-310, 2005.

[22] C. H. Nagaraja, A. Thavaneswaran, and S. S. Appadoo, "Measuring the bullwhip effect for supply chains with seasonal demand components," European Journal of Operational Research, vol. 242, no. 2, pp. 445-454, 2015.

[23] Z. Han, J. Ma, F. Si, and W. Ren, "Entropy complexity and stability of a nonlinear dynamic game model with two delays," Entropy, vol. 18, article no 317, no. 9, 2016.

[24] J. Ma and F. Si, "Complex dynamics of a continuous bertrand duopoly game model with two-stage delay," Entropy, vol. 18, article no 266, 2016. 


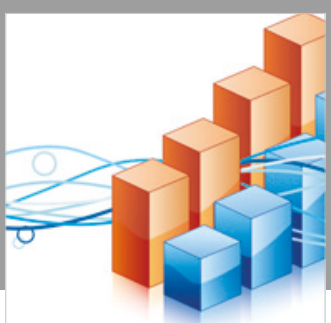

Advances in

Operations Research

\section{-n-m}
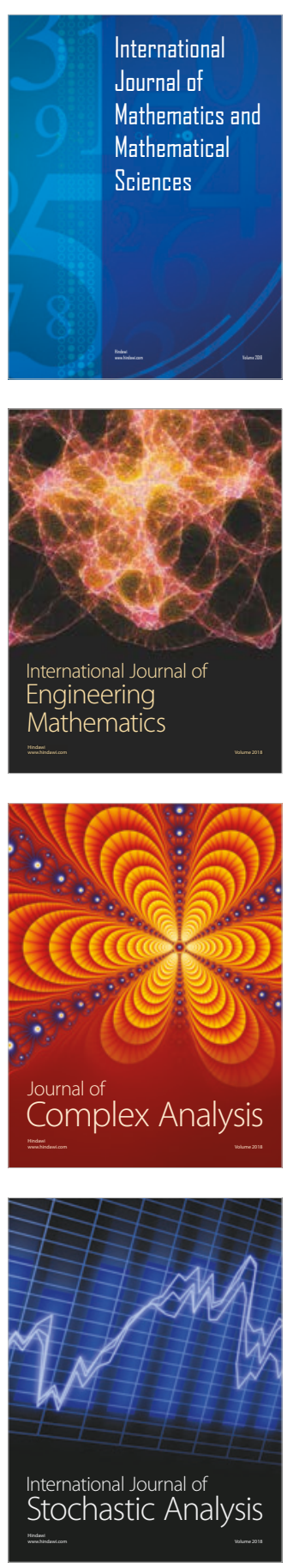
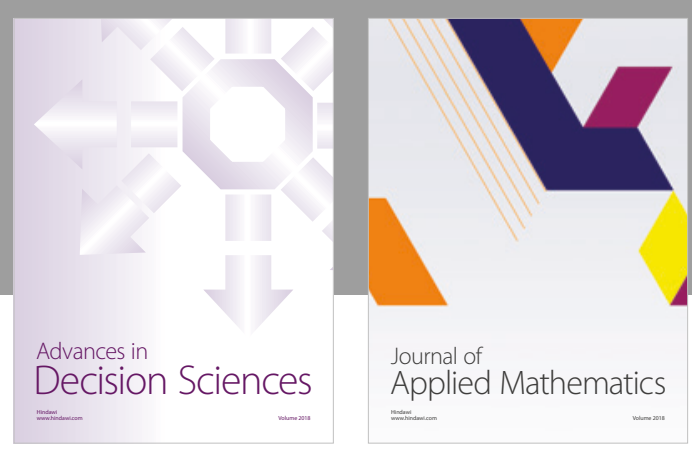

Journal of

Applied Mathematics
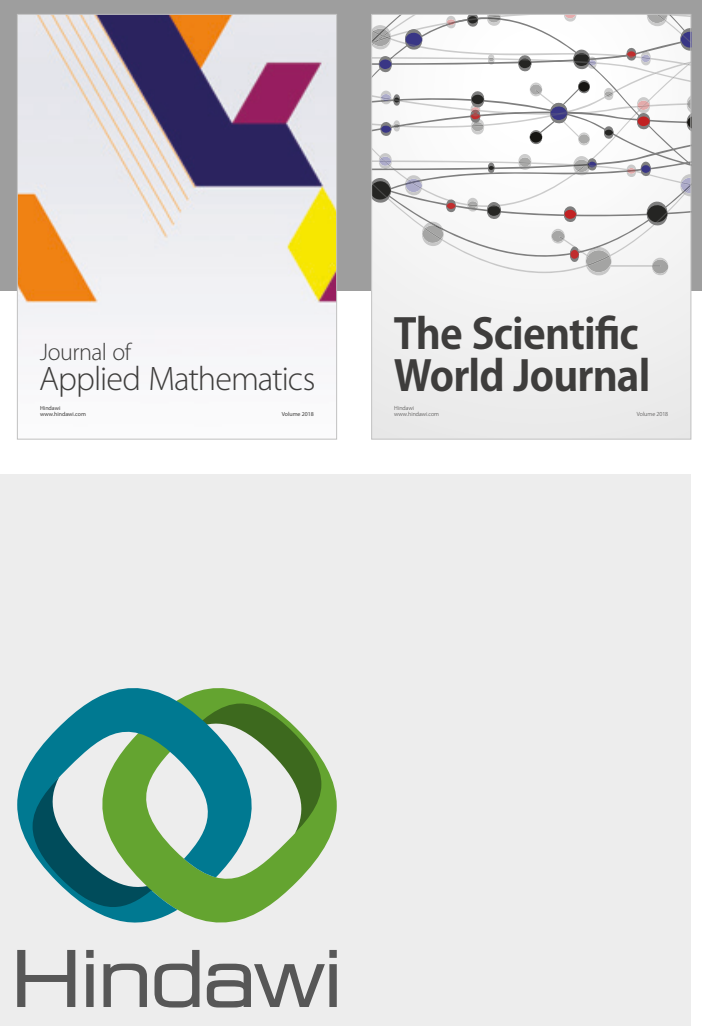

Submit your manuscripts at

www.hindawi.com

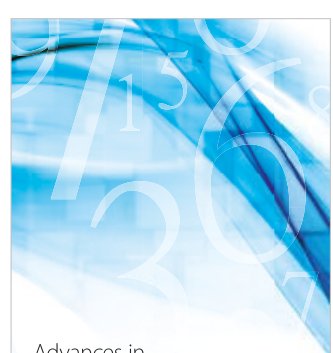

Advances in
Numerical Analysis
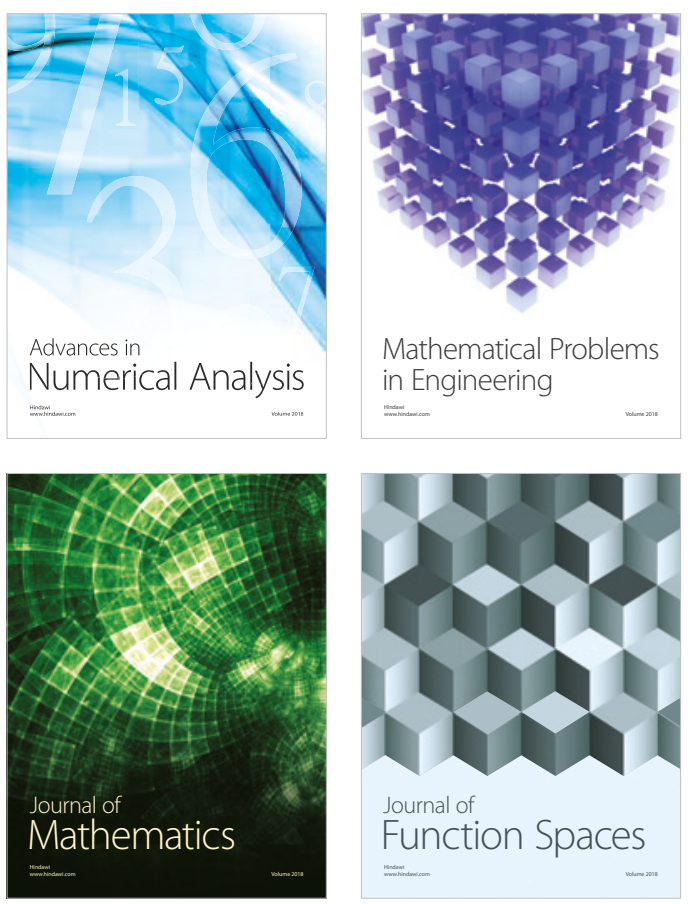

Mathematical Problems in Engineering

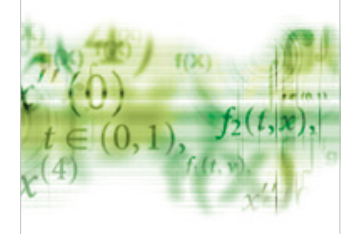

International Journal of

Differential Equations

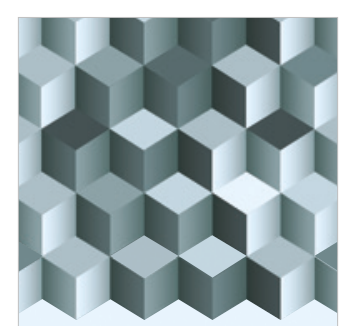

Journal of

Function Spaces
The Scientific

World Journal

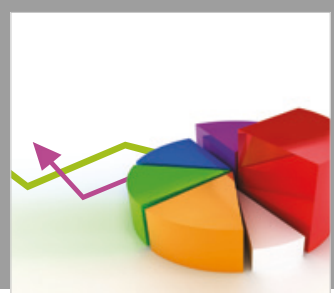

Journal of

Probability and Statistics
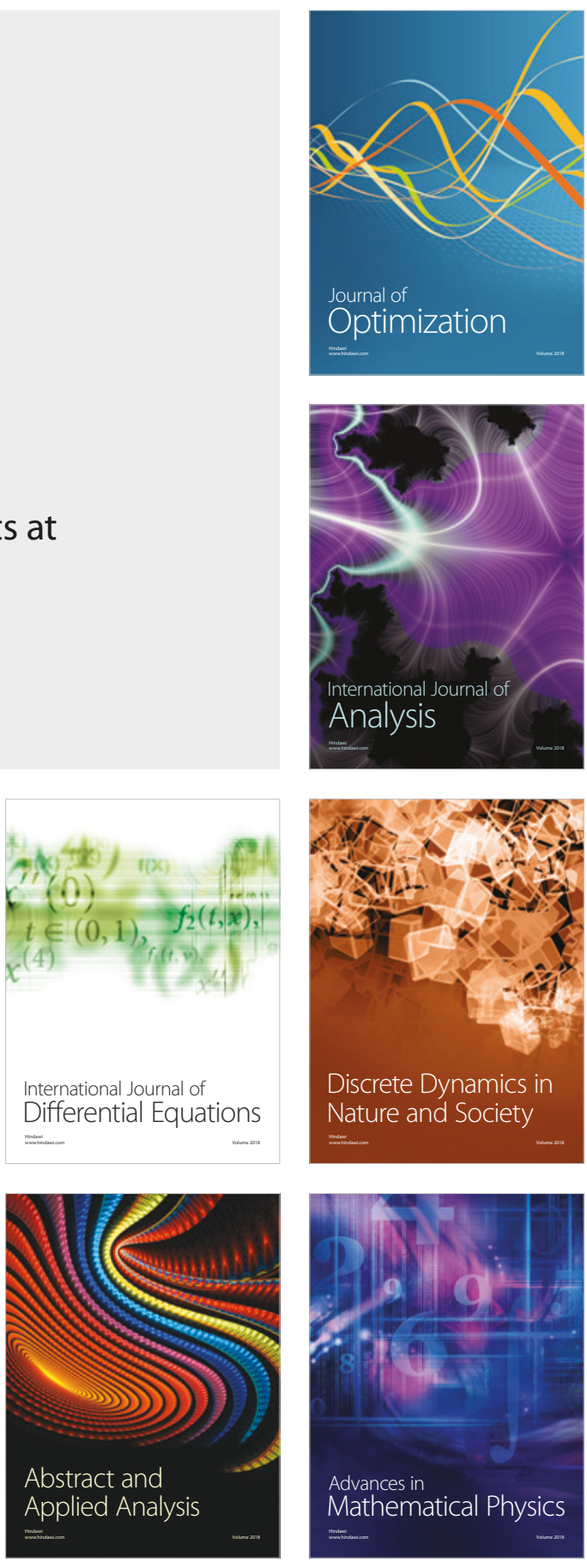